\title{
Structure and stability of pyrophyllite edge surfaces: Effect of temperature and water chemical potential
}

Kideok D. Kwon* and Aric G. Newton

Department of Geology, Kangwon National University, Chuncheon 24341, Korea

*Corresponding author: kkwon@kangwon.ac.kr

For resubmittal to Geochimica et Cosmochimica Acta 


\section{Abstract}

The surfaces of clay minerals, which are abundant in the atmospheric mineral dust, serve as an important medium to catalyze ice nucleation. The lateral edge surface of 2:1 clay minerals is postulated to be a potential site for ice nucleation. However, experimental investigations of the edge surface structure itself have been limited compared to the basal planes of clay minerals. Density functional theory (DFT) computational studies have provided insights into the pyrophyllite edge surface. Pyrophyllite is an ideal surrogate mineral for the edge surfaces of 2:1 clay minerals as it possesses no or little structural charge. Of the two most-common hydrated edge surfaces, the AC edge, (110) surface in the monoclinic polytype notation, is predicted to be more stable than the B edge, (010) surface. These stabilities, however, were determined based on the total energies calculated at $0 \mathrm{~K}$ and did not consider environmental effects such as temperature and humidity. In this study, atomistic thermodynamics based on periodic DFT electronic calculations was applied to examine the effects of environmental variables on the structure and thermodynamic stability of the common edge surfaces in equilibrium with bulk pyrophyllite and water vapor. We demonstrate that the temperature-dependent vibrational energy of sorbed water molecules at the edge surface is a significant component of the surface free energy and cannot be neglected when determining the surface stability of pyrophyllite. The surface free energies were calculated as a function of temperature from 240 to $600 \mathrm{~K}$ and water chemical potential corresponding to conditions from ultrahigh vacuum to the saturation vapor pressure of water. We show that at lower water chemical potentials (dry conditions), the AC and B edge surfaces possessed similar stabilities; at higher chemical potentials (humid conditions) the AC edge surface was more stable than the B edge surface. At high temperatures, both 
surfaces showed similar stabilities regardless of the water chemical potential. The equilibrium morphology of pyrophyllite crystals is also expected to be dependent on these two environmental variables. Surface defects may impact the surface reactivity. We discuss the thermodynamic stability of a possible Si cation vacancy defect which provides additional hydroxyl group on the surface.

\section{INTRODUCTION}

Clay minerals are abundant in atmospheric mineral dust which influences the formation and radiative properties of high altitude ice clouds through heterogeneous ice nucleation (Forster et al., 2007; Jeong and Achterberg, 2014; Pruppacher and Klett, 1997). In aerosol-climate modeling, measured data of ice nucleation efficiency for kaolinite, illite, or smectite are parameterized to represent the ice nucleation properties of mineral dust depending on the mineral composition (Hoose et al., 2008; Hoose and Möhler, 2012; Storelvmo et al., 2008). The estimation of ice nuceation properties of atomspheric mineral dusts may be improved through a mechanistic understanding of the ice formation process at clay mineral surface (Freedman, 2015; Tang et al., 2016). In particular, molecular-level characterization of ice nucleation sites and interactions of water vapor with the mineral surface can allow us to determine whether and why the ice nucleation efficiency differs among minerals. Kaolinite (1:1 clay mineral) studies have identified possible ice nucleation sites such as hydroxyl groups of basal planes and surface defects as in deposition mode nucleation, in which water vapor adsorbs first to the mineral surface and nucleates ice (Cox et al., 2013; Croteau et al., 2010; Hu and Michaelides, 2007; Welti et al., 2014). Edge surface may also play a role in the nucleation as the edge surface adsorbs water more strongly than 
the basal planes (Croteau et al., 2009) and initial ice on the mineral surface may not be crystalline but amorphous (Lamb and Verlinde, 2011). For smectite and illite (2:1 clay minerals), the lateral edge surface is postulated to be an important nucleation site (Freedman, 2015) mainly because the functional group of the exposed basal planes is hydrophobic siloxane. However, the detailed atomistic structure and thermodynamic properties of the clay mineral edge itself are not clearly characterized yet, in part due to the experimental difficulties in isolating the mineral edges and resolving the inherent disorder of the edge surfaces. The current study addresses the structure and thermodynamic stability of the edge surface.

Theoretical and molecular-level computational studies have provided insights into the structure of clay mineral edge surfaces, particularly for pyrophyllite, which primarily forms through low-grade metamorphic processes. Pyrophyllite is the prototypical 2:1 dioctahedral phyllosilicate comprising two Si tetrahedral sheets joined to an Al octahedral sheet. Because pyrophyllite lacks structural charge, the basal siloxane planes are relatively inert and the interlayer does not swell. Only the edge surfaces of pyrophyllite are reactive due to $\mathrm{OH}$ functional groups that protonate and deprotonate depending on $\mathrm{pH}$. Thus, pyrophyllite is an ideal surrogate for the edge of 2:1 clay minerals (Keren and Sparks, 1995). The application of periodic bond chain (PBC) theory (Hartman, 1973) to 2:1 dioctahedral phyllosilicates identified three types of edge surfaces (White and Zelazny, 1988). Because two of these edges are symmetrically equivalent, discussion of the edge surface can be simplified to the two edge surfaces geometries. In the monoclinic polytype, the symmetrically equivalent edges correspond to the (110) surface, and the unique edge is the (010) surface. In the triclinic polytype, the former edge coincides with the (010) surface, and the latter edge is approximately coincident with the (-110) surface (Bickmore et al., 2003; Kremleva et al., 
2012; Newton and Sposito, 2015). In the current study, we use the original edge designations of White and Zelazny (1988). The AC edge refers to the two symmetrically equivalent surfaces, and the B edge surface denotes the unique edge (Fig. 1). Geometry optimizations with density functional theory (DFT) have demonstrated how the atomistic structures of the edge surfaces differ from the bulk (Bickmore et al., 2003; Churakov, 2006). At the point of zero net proton charge (p.z.n.p.c.), each exposed tetrahedral-octahedral-tetrahedral unit of the hydrated edge surfaces possesses two silanol sites $(\equiv \mathrm{Si}-\mathrm{OH})$, an amphoteric site (三Al$\mathrm{OH}_{2}$ ), and a singly- or doubly-coordinated aluminol site depending on the surface type (三Al$\mathrm{OH}$ or $\left.\equiv \mathrm{Al}_{2}-\mathrm{OH}\right)$ (Bickmore et al., 2003; Bleam et al., 1993; White and Zelazny, 1988). The $\mathrm{Al}$ edge sites appear to have disorder in the coordination configuration, the degree of which differs depending on the edge type (Liu et al., 2015; Newton and Sposito, 2015; Tazi et al., 2012). Molecular dynamic simulations based on DFT also reported spontaneous proton transfers among the surface hydroxyls and adsorbed water molecules (Churakov, 2007; Suter et al., 2015).

Compared with the atomistic structure of surfaces, the surface stability at different temperature and humidity conditions has been little investigated, although the AC edge surface appears to be more stable than the B edge surface. The surface excess energies of hydrated pyrophyllite edges were reported in previous DFT studies (Churakov, 2006; Lavikainen et al., 2015; Martins et al., 2014). The calculated energies were relatively small and differed little amongst the surfaces considered, but the AC edge surface generally possessed a slightly lower surface energy than the B edge surface; equilibrium morphologies for pyrophyllite crystals were also predicted based on the calculated energies. Of note, the energies used in the previous studies were not free energies but total energies calculated at 0 K (i.e., surface excess energy) which did not include thermal vibrational energies. When the 
vibrational contribution is greater than the variations amongst the surface excess energies, the thermodynamic stability at ambient conditions cannot be assessed based on the excess energies calculated at $0 \mathrm{~K}$. Moreover, the energy comparison in the previous studies required that surfaces be of the same stoichiometry; stability was determined at a given surface coverage but cannot be determined amongst surfaces at different surface coverage or water vapor pressures.

In the current study, we have examined the structure and thermodynamic stability of the $\mathrm{AC}$ and $\mathrm{B}$ edge surfaces as a function of temperature and water vapor pressure through application of DFT atomistic thermodynamics (Reuter and Scheffler, 2001; Sun et al., 2003). This method links the DFT total-energy electronic structure calculations and the thermodynamic and statistical mechanic concepts to obtain insights into the surface stability as a function of the environmental variables without adjustable parameters. When a surface is in thermodynamic equilibrium with the bulk structure and a gas phase, the atomistic thermodynamics method calculates the free energy of the surface by examining solid and gas phases separately within DFT and using the DFT results as an input in the thermodynamics (Rogal and Reuter, 2007). For the first time, we calculated surface free energies of the hydrated AC and B edge surfaces of pyrophyllite at different temperatures and water chemical potentials (i.e., water vapor pressures). We show how the stability of pyrophyllite edge surfaces and the equilibrium morphology vary under different environmental conditions. The surface atomistic structures are also presented with the adsorption energies for water molecules sorbed to the surface from the vapor phase.

We also investigated the stability of surface defects. Defects on the surface create additional heterogeneity in the ice nucleation sites with likely effects on the ice nucleation 
ability of clay minerals (Croteau et al., 2010; Freedman, 2015; Schuttlefield et al., 2007). Recent classical molecular dynamics simulations and DFT simulations reported atomistic structures that possessed an inverted Si tetrahedron on some pyrophyllite edge surfaces, although the effects of these defects on mineral reactivity are unknown (Martins et al., 2014; Newton, 2012). An inverted tetrahedral configuration in the Si sheet was first proposed by Edelman and Favejee (1940; EF) as an alternate structural model for 2:1 phyllosilicates. In bulk, the inverted Si configuration would be akin to a cation vacancy defect (Grim, 1968); the missing Si cation is compensated by an interlayer (or inverted) Si and the unsaturated bonds are saturated by $\mathrm{OH}$ and $\mathrm{H}$ (Fig. 2). This inverted configuration is still occasionally used to explain some aspects of smectite reactivity as hydroxyls are introduced into the interlayer (Pusch and Karnland, 1996). We determine the feasibility of formation of these inverted Si tetrahedra (EF defects) in the pyrophyllite bulk and at the edge surface as a function of temperature and water vapor pressure.

\section{METHODS}

\subsection{DFT geometry optimizations}

All DFT calculations were performed using the CASTEP code (Clark et al., 2005) which implements DFT with periodic boundaries and a planewave basis set. We used ultrasoft pseudopotentials (Vanderbilt, 1990) to describe the strong Coulomb potentials between atomic nuclei and core electrons and the PBE functional (Perdew et al., 1996) to approximate electron exchange and correlation. A planewave basis set was expanded to a kinetic energy cutoff of $600 \mathrm{eV}$. The fast Fourier transform grid for the augmentation-charge density was set to $2,400 \mathrm{eV}$. The primitive Brillouin zone was sampled with a $6 \times 4 \times 4$ grid 
(Monkhorst and Pack, 1976) and one point in $k$ space for the unit cell and supercells, respectively. When the cutoff energy was increased to $1,000 \mathrm{eV}$, the surface excess energy of a hydrated AC edge with surface coverage $\sim 4 \mathrm{H}_{2} \mathrm{O} / \mathrm{nm}^{2}$ differed by less than $0.01 \mathrm{meV} / \AA^{2}(1$ $\mathrm{meV} / \AA^{2}=16.02 \mathrm{~mJ} / \mathrm{m}^{2}$ ), and the EF defect incorporation energy based on the total energies differed by less than $0.0015 \mathrm{eV}$ per formula unit (f.u.) for the bulk pyrophyllite structure [i.e., $\left.\mathrm{Al}_{2} \mathrm{Si}_{4} \mathrm{O}_{10}(\mathrm{OH})_{2}\right]$. The tolerance for self-consistent-field electronic energy was set at $10^{-10}$ eV/atom in an effort to obtain sufficiently accurate atomic forces on the hydrated surfaces. Geometry optimizations were performed using the two-point steepest descent algorithm (Barzilai and Borwein, 1988) and, for bulk structures, with correction for finite basis set errors (Francis and Payne, 1990). The residual atomic force was less than $0.03 \mathrm{eV} / \AA$, and the root-mean-square stress for bulk structures was less than $0.02 \mathrm{GPa}$.

Periodic slab models were created based on the $2 \times 2 \times 1$ supercell of a fully geometry-optimized pyrophyllite-1Tc structure (Lee and Guggenheim, 1981). The slab models comprised two parallel equivalent surfaces separated by a bulk mineral phase and a vacuum space. The mineral phase included four periodic bond chains or eight $\mathrm{Al}$ atomic planes parallel to the edge surfaces with a thickness of approximately $18 \AA$. Each model included a vacuum space of $10 \AA$ perpendicular to the edge surface. Thus, the simulation cell size was $10.40 \times 28.05 \times 10.12 \AA$ for the AC edge surface model and $10.45 \times 27.54 \times 10.12 \AA$ for the B edge surface model. We calculated the surface excess energy of the hydrated AC edge with surface coverage $\sim 4 \mathrm{H}_{2} \mathrm{O} / \mathrm{nm}^{2}$ whose thickness was approximately $27 \AA$ (i.e., a slab model containing 6 periodic bond chains or $12 \mathrm{Al}$ atomic planes). The energy differed by less than $0.1 \mathrm{meV} / \AA^{2}$ from the current model. We also tested whether the current vacuum space is sufficiently large to minimize spurious interactions between periodic cells. The surface excess 
energy of a hydrated AC edge surface (coverage $\sim 8 \mathrm{H}_{2} \mathrm{O} / \mathrm{nm}^{2}$ ) that included a $20 \AA$ vacuum space differed by less than $0.1 \mathrm{meV} / \AA^{2}$ from the current model. The coordinates of all ions were relaxed except for those of the four central $\mathrm{Al}$ in the slab during the geometry optimization of the slab models.

The initial atomic termination of $\mathrm{AC}$ and $\mathrm{B}$ edge surfaces followed the surfaces defined by the application of periodic bond chain theory to $2: 1$ dioctahedral phyllosilicates (Hartman, 1973; White and Zelazny, 1988). Each pristine surface possesses two 3coordinated $\mathrm{Si}$, two dangling $\mathrm{O}$, and two 5-coordinated $\mathrm{Al}$ per side of the slab (Fig. 1a and d). The chemical formula of the slab model was $\mathrm{Al}_{16} \mathrm{Si}_{32} \mathrm{O}_{80}(\mathrm{OH})_{16}$. The pristine edge surface was hydrated by dissociative, molecular, and $\mathrm{H}$-bond adsorption of $\mathrm{H}_{2} \mathrm{O}$ molecules to reactive edge sites. An integer number of water molecules were adsorbed to the surface to maintain the p.z.n.p.c., in accordance with the surface protonation scheme proposed by White and Zelazny (1988) and Bleam et al. (1993). In the dissociative adsorption of $\mathrm{H}_{2} \mathrm{O}$ to the surface, a hydroxyl and a proton saturated the unsaturated bonds of the Si tetrahedra of the pristine surface [i.e., $\equiv \mathrm{Si}(1)-\mathrm{OH}$ and $\equiv \mathrm{Si}(2) \mathrm{O}-\mathrm{H}$ in Fig. 1]. In molecular adsorption, a $\mathrm{H}_{2} \mathrm{O}$ molecule was added to the 5-coordinate $\mathrm{Al}$. Thus, an edge $\mathrm{Al}$ in octahedral coordination with $\mathrm{O}$ was created. For $\mathrm{H}$-bonds, $\mathrm{H}_{2} \mathrm{O}$ interacts as a $\mathrm{H}$ donor with the bridging $\mathrm{O}$ between $\mathrm{Si}$ and $\mathrm{Al}$ sheets $(\equiv \mathrm{Al}-\mathrm{O}-\mathrm{Si} \equiv)$ or as a $\mathrm{H}$ acceptor with the structural $\mathrm{OH}$ of the $\mathrm{Al}$ octahedral sheet exposed to the $\mathrm{AC}$ edge surface $\left(\equiv \mathrm{Al}-\mathrm{OH}_{2}\right)$. As the bridging $\mathrm{O}$ of the $\mathrm{B}$ edge is inaccessible by water molecules, water formed $\mathrm{H}$-bonds with $\equiv \mathrm{Al}-\mathrm{OH}, \equiv \mathrm{Al}-\mathrm{OH}_{2}$, and $\equiv \mathrm{Si}-\mathrm{OH}$ surface sites instead. Water molecules were added incrementally to edge surfaces until the surface coverage reached $8 \mathrm{H}_{2} \mathrm{O} / \mathrm{nm}^{2}$ and $6 \mathrm{H}_{2} \mathrm{O} / \mathrm{nm}^{2}$ (approximately a monolayer of adsorbed water) for the AC and B edge surfaces, respectively. At the maximum coverage, the chemical 
formulas were $\mathrm{Al}_{16} \mathrm{Si}_{32} \mathrm{O}_{112} \mathrm{H}_{48}$ and $\mathrm{Al}_{16} \mathrm{Si}_{32} \mathrm{O}_{108} \mathrm{H}_{40}$, respectively.

2.2. Differential adsorption energy and surface free energy calculations

The differential adsorption energy of water $\left(H_{\text {ads }}\right)$ was calculated as

$$
H_{\text {ads }}=-\left[E_{2(m+1)}-E_{2 m}-2 E_{\mathrm{H}_{2} \mathrm{O}}\right] / 2
$$

where $E_{2(m+1)}$ and $E_{2 m}$ are the total energies of the slab model hydrated by $m+1$ and $m \mathrm{H}_{2} \mathrm{O}$ molecules per edge side $(m=0,1,2,3, \ldots)$, respectively. $E_{\mathrm{H} 2 \mathrm{O}}$ is the total energy of an isolated $\mathrm{H}_{2} \mathrm{O}$ molecule calculated in a cubic cell of length $25 \AA$.

The surface free energy, $\gamma(T, p)$, of the hydrated surfaces at a given temperature $T$ and gas-phase pressure $p$ is given by

$$
\gamma(T, p)=\frac{1}{2 A}\left[G_{\text {surf }}(T, p)-\sum_{i} N_{i} \mu_{i}(T, p)\right]
$$

where $A$ is the surface area of one side of the slab model, $G_{\text {surf }}$ is the Gibbs energy of the surface, and $N_{i}$ and $\mu_{i}$ are the number and chemical potential of constituent atom $i$ (in this study, $i=\mathrm{Si}, \mathrm{Al}, \mathrm{O}$ or $\mathrm{H}$ ), respectively. The surface free energy was calculated at $T=240$, 300, 400, and $600 \mathrm{~K}$, which bracket two environmental conditions. The temperatures at which cirrus clouds form in the atmosphere range from 220 to $260 \mathrm{~K}$ (Welti et al., 2014). Dehydroxylation of the bulk pyrophyllite is observed at the temperatures of 650 to $1200 \mathrm{~K}$ (Drits et al., 2011; Heller et al., 1962). The Gibbs energy $(G)$ is defined as

$$
G=E^{\mathrm{tot}}+F^{\mathrm{vib}}-T S^{\mathrm{conf}}+p V
$$

where $E^{\text {tot }}, F^{\mathrm{vib}}, S^{\mathrm{conf}}$, and $p V$ are total energy, vibrational energy, configurational entropy, and pressure-volume term, respectively. The $p V$ term in equation (3) contributes negligibly to the 
surface free energy (e.g., much less than $0.1 \mathrm{meV} / \AA^{2}$ at $100 \mathrm{~atm}$ of the partial pressure of gas) (Reuter and Scheffler, 2001). The $S^{\text {conf }}$ can be neglected because specific surface configurations are compared here. The Gibbs energy can then be approximated by the sum of the total energy and vibrational energy: $G \approx E^{\text {tot }}+F^{\mathrm{vib}}$. The vibrational energy is expressed as

$$
F^{\mathrm{vib}}=E^{\mathrm{ZPE}}+E^{\mathrm{vib}}-T S^{\mathrm{vib}}
$$

where $E^{\mathrm{ZPE}}, E^{\mathrm{vib}}$, and $S^{\mathrm{vib}}$ are the zero point energy, vibrational internal energy, and vibrational entropy at a given $T$, respectively.

When the surface and bulk pyrophyllite are at equilibrium, the Gibbs energy of bulk pyrophyllite $\left[G_{\text {pyro }}^{\text {bulk }} ; \mathrm{Al}_{4} \mathrm{Si}_{8} \mathrm{O}_{20}(\mathrm{OH})_{4}\right]$ is equal to its chemical potential which is the stoichiometric sum of the constituent atom chemical potentials:

$$
G_{\text {pyro }}^{\text {bulk }}=\mu_{\text {pyro }}^{\text {bulk }}=4 \mu_{\mathrm{Al}}+8 \mu_{\mathrm{Si}}+24 \mu_{\mathrm{O}}+4 \mu_{\mathrm{H}}
$$

If equation (5) is substituted in equation (2), then the $\gamma(T, p)$ of a surface adsorbed by $m \mathrm{H}_{2} \mathrm{O}$ molecules becomes

$$
\gamma(T, p)=\frac{1}{2 A}\left[G_{\mathrm{surf}}(T)-\frac{N_{\mathrm{Al}}}{4} G_{\mathrm{pyro}}^{\text {bulk }}(T)-2 m \mu_{\mathrm{H}}(T, p)-m \mu_{\mathrm{o}}(T, p)\right]
$$

In an environment where $\mathrm{H}_{2} \mathrm{O}_{(\mathrm{g})}$ is a dominant gas phase, $\mu_{\mathrm{H}}$ is equal to $1 / 2\left(\mu_{\mathrm{H} 2 \mathrm{O}}+\mu_{\mathrm{O}}\right)$; thus the surface free energy is divided into two parts: i) the Gibbs energy difference of solid phases and ii) the chemical potential of a gas phase,

$$
\gamma(T, p)=\frac{1}{2 A}\left[G_{\text {surf }}(T)-\frac{N_{\mathrm{Al}}}{4} G_{\text {pyro }}^{\text {bulk }}(T)\right]-\Theta \mu_{\mathrm{H}_{2} \mathrm{O}_{(g)}}(T, p)
$$


where $\Theta$ is the coverage of water molecules on the surface $(m / 2 A)$ and $N_{\mathrm{Al}}=16$ in the current study. The equilibrium morphology of pyrophyllite was predicted based on the calculated surface free energies using the software WulffMaker (Zucker et al., 2012).

The Gibbs energy difference of solid phases in equation (7) can be approximated by a total energy difference $\left(\Delta E^{\text {tot }}\right)$ if the vibrational energy difference $\left(\Delta F^{\mathrm{vib}}\right)$ is sufficiently small to be neglected. The $\Delta F^{\mathrm{vib}}$ value of a hydrated surface is primarily from the vibrational contribution of water adsorbed on the surface (Sun et al., 2003). We estimated the vibrational contribution of the adsorbates to the surface energy $\left(\gamma^{\mathrm{vib}}\right)$ by calculating the force constant matrix of the $\mathrm{H}_{2} \mathrm{O}$ molecules adsorbed to the surface within the harmonic approximation. The force constant matrix was calculated using the finite displacement method (Ackland et al., 1997) at the $\Gamma$ point with the adsorbent surface coordinates fixed. Each adsorbate atom was displaced by $\pm 0.005 \AA$ along the Cartesian directions. The force constant matrix was Fourier transformed into the dynamical matrix, and its eigenvalues (i.e., frequencies) were then integrated to compute the vibrational contribution (i.e., enthalpy and vibrational entropy) at a given temperature. A convergence test is prohibitively expensive for the calculated $\gamma^{\text {vib }}$ (hence the surface free energy) with respect to the surface supercell size used in the finite displacement method. Instead the upper bound on the numerical accuracy of the surface free energy was estimated to be in the order of $1 \mathrm{meV} / \AA^{2}$ based on the averaged $\gamma^{\text {vib }}$ per sorbed $\mathrm{H}_{2} \mathrm{O}\left(\sim 6 \mathrm{meV} / \AA^{2}\right)$ of AC edge surfaces at $300 \mathrm{~K}$ (Fig. S1).

The chemical potential for an ideal gas of water $\left(\mu_{\mathrm{H} 2 \mathrm{O}}\right)$ at $T$ and $p$ was obtained by integrating along the temperature and pressure change from a reference state $\mu_{\mathrm{H} 2 \mathrm{O}}\left(T^{\mathrm{o}}, p^{\mathrm{o}}\right)$ (Reuter and Scheffler, 2001), 


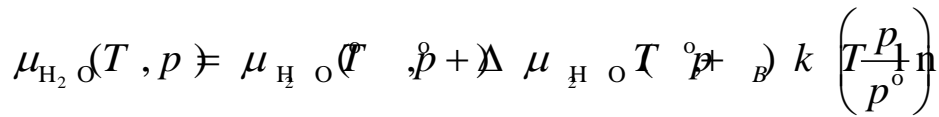

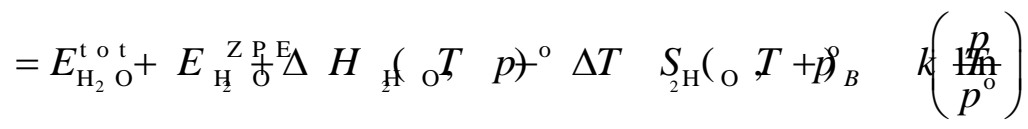

where $E^{\mathrm{tot}}$ and $E^{\mathrm{ZPE}}$ are the total energy and zero point energy, respectively, of an isolated $\mathrm{H}_{2} \mathrm{O}$ molecule at $T^{\mathrm{o}}=0 \mathrm{~K}$ and $p^{\mathrm{o}}=1 \mathrm{~atm}$. The quantities of $\Delta H\left(T, p^{\mathrm{o}}\right)=H\left(T, p^{\mathrm{o}}\right)-H\left(0 K, p^{\mathrm{o}}\right)$ and $\Delta S\left(T, p^{\circ}\right)=S\left(T, p^{\circ}\right)-S\left(0 K, p^{\circ}\right)$, which are independent of the choice of energy zero, were obtained from thermodynamics tables (Chase, 1998). We calculated the surface free energy as a function of the water chemical potential with respect to the sum $E^{\text {tot }}+E^{\mathrm{ZPE}}$ for a water molecule $\left(\Delta \mu_{\mathrm{H} 2 \mathrm{O}}\right)$. The lower limit of the chemical potential was set to the condition of ultrahigh vacuum $\left(p_{\mathrm{H} 2 \mathrm{O}}=10^{-11}-10^{-13} \mathrm{~atm}\right)$. The upper limit was taken from the saturation vapor pressure at the considered temperatures $(0.00037,0.03,2.47$, and 133.5 atm for 240 , 300,400 , and $600 \mathrm{~K}$, respectively), which corresponds to water chemical potential of -0.53 $\mathrm{eV},-0.57 \mathrm{eV},-0.65 \mathrm{eV}$, and $-0.86 \mathrm{eV}$, respectively.

\subsection{EF defect calculations}

The bulk model with the EF-defect was created through the dissociative sorption of one $\mathrm{H}_{2} \mathrm{O}$ molecule per inverted $\mathrm{Si}$ in the interlayer of pyrophyllite bulk structure (Fig. 2). An $\mathrm{OH}$ is bonded to a Si to form an inverted Si tetrahedron in the interlayer; an $\mathrm{H}$ saturates the unsaturated $\mathrm{O}$ of the $\mathrm{Al}$ that results from the inversion of the Si tetrahedron (Grim, 1968). The overall chemical formula for the defect model was $\mathrm{Al}_{4} \mathrm{Si}_{8} \mathrm{O}_{20}(\mathrm{OH})_{4} \cdot m\left(\mathrm{H}_{2} \mathrm{O}\right)(m=$ the number of water molecules). The stability of the EF defect was evaluated by calculating the free energy difference $\left(\Delta G_{\mathrm{EF}}\right)$ of the defect incorporation reaction described as

$$
\text { pyrophyllite }_{(\mathrm{s})}+m \mathrm{H}_{2} \mathrm{O}_{(\mathrm{g})}=\text { EF-pyrophyllite }(\mathrm{s})
$$


where pyrophyllite $(\mathrm{s})$ represents the defect-free pyrophyllite (Lee and Guggenheim, 1981) and EF-pyrophyllite (s) $_{\text {is }}$ pyrophyllite with the defect. The $\Delta G_{\mathrm{EF}}$ was calculated as a function of temperature and the vapor pressure according to

$$
\Delta G_{\mathrm{EF}}=\left[G_{\mathrm{EF}}(T)-\frac{N_{\mathrm{Al}}}{4} G_{\mathrm{pyro}}(T)\right]-\frac{N_{\mathrm{Al}}}{4} m \mu_{\mathrm{H}_{2} \mathrm{O}(\mathrm{g})}(T, p)
$$

where $G_{\mathrm{EF}}$ and $G_{\mathrm{pyro}}$ are the free energies approximated as $G \approx E^{\mathrm{tot}}+F^{\mathrm{vib}}$ for the EF-defect pyrophyllite and the defect-free pyrophyllite, respectively, $N_{\mathrm{Al}}$ is the number of $\mathrm{Al}$ in the defect model, and $\mu_{\mathrm{H} 2 \mathrm{O}}(T, p)$ is the chemical potential of $\mathrm{H}_{2} \mathrm{O}_{(\mathrm{g})}$. The free energy difference is reported per the formula unit (f.u.) of bulk pyrophyllite, $\mathrm{Al}_{2} \mathrm{Si}_{4} \mathrm{O}_{10}(\mathrm{OH})_{2} . F^{\mathrm{vib}}$ was estimated by the finite displacement phonon calculation (Ackland et al., 1997) with a supercell containing 80 atoms for pure pyrophyllite and 163 atoms for the EF-pyrophyllite. When a supercell containing 640 atoms was used for pure pyrophyllite, the $F^{\mathrm{vib}}$ differed by only 0.012 eV/f.u. from the calculation using 80 atoms. This tests leads to the numerical accuracy of the $\Delta G_{\mathrm{EF}}$ in the order of $0.01 \mathrm{eV} / \mathrm{f} . \mathrm{u}$. This uncertainty does not include possible errors that may be introduced by the harmonic approximation for phonon calculations or the approximation for electronic exchange and correlation. For the EF defect surface model, a Si tetrahedron at the AC edge surface $\left(\Theta=3.9 \mathrm{H}_{2} \mathrm{O} / \mathrm{nm}^{2}\right.$ ) was initially rotated 90 degrees (i.e., inverted $\mathrm{Si}$ ) such that the $\mathrm{Al}-\mathrm{O}$ bond of the bridging surface $\mathrm{O}$ site $\left(\mathrm{O}_{\mathrm{sb}}\right)$ was cleaved to produce fivecoordinated $\mathrm{Al}$ and a dangling $\mathrm{Si}-\mathrm{O}$ bond (i.e., $\equiv \mathrm{Al}-\mathrm{O}-\mathrm{Si} \equiv \rightarrow \equiv \mathrm{Al}+\mathrm{O}-\mathrm{Si} \equiv$ ) with the $\mathrm{Si}-\mathrm{O}$ bond parallel to the basal plane. The EF defective surface model used a $10.40 \times 28.05 \times$ $10.12 \AA$ or $20.80 \times 38.05 \times 10.12 \AA$ cell depending on a defect ratio (i.e., the number of inverted Si: the number of possible Si inversions in the model). 


\section{RESULTS}

\subsection{Bulk structure}

The lattice parameters of the geometry-optimized pyrophyllite bulk structure are summarized in Table 1 . The lattice parameters were slightly larger than the experimental data of Lee and Guggenheim (1981) within $1 \%$ error, with the exception of the $c$ axis parameter ( $8 \%$ error). The large error associated with the $c$ axis of layer-type minerals, in which van der Waals (vdW) interactions dominate between the layers, is common in standard DFT calculations using the semilocal approximation for exchange-correlation energy, such as the PBE functional we used in this study. Alternatively, a DFT method with dispersion correction (DFT-D) often achieves better agreement with the experimentally determined $c$ axis of clay minerals such as pyrophyllite (Tunega et al., 2012; Voora et al., 2011). Using the DFT-D method (Grimme, 2006), we also demonstrate better agreement with the experiment (Table 1). The structural parameters for the bulk and surfaces reported hereafter are based on standard DFT calculations that do not include empirical parameters to describe the vdW interactions between atoms. The average $\mathrm{Si}-\mathrm{O}$ distance, $d(\mathrm{Si}-\mathrm{O})$, was $1.632 \AA$ for the apical Si-O bonds and $1.618 \AA$ for the basal $\mathrm{Si}-\mathrm{O}$ bonds. The average $\mathrm{Al}-\mathrm{O}$ distance, $d(\mathrm{Al}-\mathrm{O})$, was $1.898 \AA$ for the $\mathrm{Al}-\mathrm{OH}$ bonds and $1.935 \AA$ for the Al-O bonds. Similar to the lattice parameters, these calculated bond distances are within $\sim 1 \%$ of the reported experimental values for pyrophyllite.

\subsection{Surface hydration and differential adsorption energy}

Geometry optimization of the pristine AC edge surface produced dramatic changes in the structure (Fig. 1). The initially three-coordinated surface Si(1) contracted toward the bulk and became four-coordinated by forming a new bond with the structural $\mathrm{OH}$ of the ditrigonal 
cavity which resulted in the breaking of the original $\mathrm{Al}-\mathrm{OH}$ bond. The $\mathrm{OH}$ newly associated with $\mathrm{Si}(1)$ was positioned above the plane of the other hydroxyls by approximately $0.6 \AA$ (Fig. 1b). Whereas the $\mathrm{Si}(1)$ became fully coordinated through rearrangement of the surface and the formation of a new bond with the structural hydroxyl, the dangling $\mathrm{O}$ of $\mathrm{Si}(2)$ became saturated by bonding with the surface Al that lost the structural hydroxyl to $\operatorname{Si}(1)$. This saturation of $\mathrm{O}$ occurs through slight rotation of the $\mathrm{Si}(2)$ tetrahedron toward the edge $\mathrm{Al}$. This bond formation maintained the surface $\mathrm{Al}$ in a trigonal bipyramidal coordination. The surface $\mathrm{Al}$ was displaced by $0.5 \AA$ in the $\mathrm{z}$-coordinate from the $\mathrm{Al}$ atomic plane. Whereas the AC edge surface undergoes significant reconstructions after geometry optimization (Figs. 1a and $b$ ), the pristine B edge surfaces exhibited only minimal relaxation of the surface atomic structure except for the orientation of the surface Al hydroxyl (三Al-OH) (Figs. 1d and e). On the B edge surface, undercoordinated $\mathrm{Si}(1)$ contracted toward the bulk side similarly to the $\mathrm{Si}(1)$ on the AC edge surface but less severely. The $\mathrm{Si}(1)$ on the B edge did not form a new bond with structural $\mathrm{OH}$ of $\mathrm{Al}$ octahedra and remained in three-fold coordination. The dangling $\mathrm{Si}(2)-\mathrm{O}$ bond also remained unsaturated and did not interact with the neighboring surface five-fold Al.

The stability of the pristine edge surface is increased through the adsorption of $\mathrm{H}_{2} \mathrm{O}$ molecules to the undercoordinated cations and unsaturated bonds. We examined the energetics of surface hydration and corresponding structural changes through a systematic increase in water surface coverage $(\Theta)$ up to a total of eight molecules per AC edge surface $\left(\Theta=7.7 \mathrm{H}_{2} \mathrm{O} / \mathrm{nm}^{2}\right)$ in the present surface model. Differential adsorption energy $\left(H_{\text {ads }}\right)$ dramatically decreased when the surface coverage exceeded $2 \mathrm{H}_{2} \mathrm{O} / \mathrm{nm}^{2}$ (Fig. 3). When water binds to the surface via dissociative adsorption $\left(\Theta \cong 1-2 \mathrm{H}_{2} \mathrm{O} / \mathrm{nm}^{2}\right)$, the $H_{\text {ads }}$ was 260 
$\mathrm{kJ} / \mathrm{mol}$. The $H_{\text {ads }}$ decreased significantly to $76 \mathrm{~kJ} / \mathrm{mol}$ for molecular adsorption $(\Theta \cong 3-4$ $\mathrm{H}_{2} \mathrm{O} / \mathrm{nm}^{2}$ ). The $H_{\text {ads }}$ further decreased to 62 and $45 \mathrm{~kJ} / \mathrm{mol}$ when water formed H-bonds with surface groups at $\Theta \cong 5-6 \mathrm{H}_{2} \mathrm{O} / \mathrm{nm}^{2}$ and $\Theta \cong 7-8 \mathrm{H}_{2} \mathrm{O} / \mathrm{nm}^{2}$, respectively. The $H_{\text {ads }}$ for the dissociative sorption compares favorably with the activation energy for the dehydroxylation of silica (254 kJ/mol) estimated based on infrared spectroscopic experiments (Yongheng and Zhenan, 2006). Using thermogravimetric analysis, Drits et al. (2011) estimated the activation energy for dehydroxylation of $\equiv \mathrm{Al}_{2}-\mathrm{OH}$ groups in bulk pyrophyllite at $T>700 \mathrm{~K}$. This activation energy ranged from 120 to $160 \mathrm{~kJ} / \mathrm{mol}$. This estimate is bracketed by our calculated $H_{\text {ads }}$ for dissociative and molecular adsorption to the surface.

The water heat of adsorption depends on the edge surface (Fig. 3). The $H_{\text {ads }}$ of the B edge surfaces differed significantly from that of the AC edge surfaces, although the B edge surfaces also showed greater $H_{\text {ads }}$ for dissociative adsorption $(520 \mathrm{~kJ} / \mathrm{mol})$ than for molecular adsorption $(38 \mathrm{~kJ} / \mathrm{mol})$. The $H_{\text {ads }}$ for molecular adsorption on the B edge surfaces was much lower than the corresponding $H_{\text {ads }}$ and $H_{\text {ads }}$ for water H-bonds on the AC edge surfaces (38 $\mathrm{kJ} / \mathrm{mol}$ vs. $46-76 \mathrm{~kJ} / \mathrm{mol}$ ). This energy comparison implies that the B-edge surface $\mathrm{Al}$ more easily loses a molecularly adsorbed water molecule (i.e., becomes a five-fold coordinate Al) than the $\mathrm{Al}$ on the AC edge surfaces. Indeed, when we geometry-optimized the surfaces with $\Theta \cong 6 \mathrm{H}_{2} \mathrm{O} / \mathrm{nm}^{2}$ (i.e., surfaces with $\mathrm{H}$-bonded water molecules), one out of four $\mathrm{Al}$ sites on the $\mathrm{B}$ edge was five-fold coordinated, whereas all $\mathrm{Al}$ on the $\mathrm{AC}$ edge were in six-fold coordination (Fig. 1c and f). The change in the coordination number (six to five) of the surface $\mathrm{Al}$ is reflected in the slightly greater $H_{\text {ads }}$ of the $\mathrm{B}$ edge at $\Theta \cong 6 \mathrm{H}_{2} \mathrm{O} / \mathrm{nm}^{2}$ than at molecular adsorption $\left(\Theta=3-4 \mathrm{H}_{2} \mathrm{O} / \mathrm{nm}^{2}\right)$. Liu et al. (2015) recently calculated the free energy for water desorption from the $\mathrm{Al}$ site on both edge surfaces by using constrained 
molecular dynamics based on DFT. They predicted that 5- and 6-fold Al are both stable on the $\mathrm{B}$ edge surface, but only 6 -fold $\mathrm{Al}$ is stable on the $\mathrm{AC}$ edge surface.

At the lowest water coverage, the surface is stabilized by dissociative adsorption of a water molecule; a hydroxyl binds to the three-coordinated $\mathrm{Si}(1)$ and a proton binds to the unsaturated $\mathrm{O}$ of the edge $\mathrm{Si}(2)$. In the edge surface model, two $\mathrm{H}_{2} \mathrm{O}$ molecules were necessary to saturate all undercoordinated $\mathrm{Si}$ and unsaturated $\mathrm{O}$, corresponding to the surface coverage of $1.9 \mathrm{H}_{2} \mathrm{O} / \mathrm{nm}^{2}$. Unlike the pristine surface, no contraction occurred on the hydrated AC surfaces. The dissociative chemisorption further prevented surface reconstruction, and the surface $\mathrm{Si}$, hydroxyl of $\mathrm{Al}$ octahedra, and edge $\mathrm{Al}$ remained almost in their corresponding positions in bulk. The bond distance between $\mathrm{Si}$ and $\mathrm{OH}$ at the surface $(1.62-1.63 \AA)$ was not much different from the distance between $\mathrm{Si}$ and basal O ( $\left.\mathrm{O}_{\text {basal }}\right)$ in the bulk (1.62 $\AA$ ). The bond distance of the surface $\mathrm{Si}$ with $\mathrm{O}_{\mathrm{sb}}$ (apical O exposed to surface) was much shorter than the corresponding distance between $\mathrm{Si}$ and apical $\mathrm{O}$ in the bulk (1.60 $\AA$ vs. $1.65 \AA$ ). These results are in agreement with a previous DFT study of the AC edge with the same coverage (Churakov, 2006). In that study, the $d(\mathrm{Si}-\mathrm{OH})$ and $d\left(\mathrm{Si}-\mathrm{O}_{\mathrm{sb}}\right)$ on the surface were $1.64 \AA$ and $1.62 \AA$, respectively; the $d\left(\mathrm{Si}-\mathrm{O}_{\text {basal }}\right)$ and $d\left(\mathrm{Si}-\mathrm{O}_{\text {apical }}\right)$ in the bulk were $1.63 \AA$ and $1.65 \AA$, respectively. Surface hydration appears to influence the orientation of the structural $\mathrm{OH}$ of the AC edge surface but not the B edge surface. The out-of-plane angle of structural $\mathrm{OH}$ with respect to the basal plane was $25^{\circ}$ in the bulk. The angle for structural $\mathrm{OH}$ between the $2^{\text {nd }}$ and $3^{\text {rd }}$ outermost $\mathrm{Al}$ atomic planes was $10^{\circ}$ in the $\mathrm{AC}$ edge surface model and nearly $25^{\circ}$ in the B edge surface model (Figs. 1c and f).

At a surface coverage of $3-4 \mathrm{H}_{2} \mathrm{O} / \mathrm{nm}^{2}$, a $\mathrm{H}_{2} \mathrm{O}$ molecule can bind to a five-fold surface Al via molecular or dissociative adsorption. When a water molecule adsorbs without 
dissociation to the $\mathrm{Al}$ site (i.e., $\equiv \mathrm{Al}-\mathrm{OH}_{2}$ ) of the $\mathrm{AC}$ edge surface to form an octahedral $\mathrm{Al}$, $\mathrm{H}_{2} \mathrm{O}$ draws the $\mathrm{Al}$ slightly away from the bulk; the $\equiv \mathrm{Al}-\mathrm{OH}_{2}$ bond distance was $2.02 \AA$. The molecular adsorption increased the distance between the $\mathrm{Al}$ and $\mathrm{O}_{\mathrm{sb}}$ from $1.76 \AA$ to $1.80 \AA$. Churakov (2006) reported $2.07 \AA$ and $1.81 \AA$ for the $d\left(\mathrm{Al}-\mathrm{OH}_{2}\right)$ and $d\left(\mathrm{Al}-\mathrm{O}_{\mathrm{sb}}\right)$, respectively. If the water molecule dissociatively adsorbs to the $\mathrm{Al}$ site, $\mathrm{OH}$ would bind to $\mathrm{Al}$ (i.e., $\equiv \mathrm{Al}-$ $\mathrm{OH})$ and $\mathrm{H}$ would bind to $\mathrm{O}_{\mathrm{sb}}\left[\right.$ i.e., $\left.\equiv \mathrm{Al}-\mathrm{O}_{\mathrm{sb}} \mathrm{H}-\mathrm{Si}(1) \equiv\right]$. The differential adsorption energy $\left(H_{\text {ads }}\right)$ for the dissociative adsorption was only $31 \mathrm{~kJ} / \mathrm{mol}$, whereas $H_{\text {ads }}$ for molecular adsorption was as much as $79 \mathrm{~kJ} / \mathrm{mol}$. Thus, molecular adsorption is favored over the dissociative adsorption at the undercoordinated Al site, a result consistent with the general protonation scheme proposed for pyrophyllite surfaces at the point of zero net proton charge (Bickmore et al., 2003; Bleam et al., 1993; Churakov, 2007; Liu et al., 2014). On the B edge surface, the molecular adsorption to the $\mathrm{Al}$ site brought back the orientation of the surface $\mathrm{OH}$ $(\equiv \mathrm{Al}-\mathrm{OH})$ to the corresponding in-bulk orientation. For the present surface model, two water molecules were needed to saturate the undercoordinated surface Al, resulting in a total surface coverage of 3.9 and $3.8 \mathrm{H}_{2} \mathrm{O} / \mathrm{nm}^{2}$ for the AC edge and B edge surface, respectively.

Water molecules added to the surface in excess of $\sim 4 \mathrm{H}_{2} \mathrm{O} / \mathrm{nm}^{2}$ are associated with the surface through H-bonds. For the AC edge surface, two water molecules were associated with the $\mathrm{O}_{\text {sb }}$ sites $\left(\Theta=5.8 \mathrm{H}_{2} \mathrm{O} / \mathrm{nm}^{2}\right)$, and two additional water molecules were associated with the $\mathrm{O}_{\mathrm{s}} \mathrm{H}$ sites $\left(\Theta=7.7 \mathrm{H}_{2} \mathrm{O} / \mathrm{nm}^{2}\right)$. These molecules can be $\mathrm{H}$ donors to the $\mathrm{O}_{\text {sb }}$ site or $\mathrm{H}$ acceptors from the structural $\mathrm{OH}\left(\mathrm{O}_{\mathrm{s}} \mathrm{H}\right.$ or $\left.\equiv \mathrm{Al}_{2}-\mathrm{O}_{\mathrm{s}} \mathrm{H}\right)$ of the exposed $\mathrm{Al}$ octahedra (see Fig. 1). The H-bond distance was $1.6 \AA$ for the $\mathrm{O}_{\mathrm{sb}}$ site and $1.9 \AA$ for the $\mathrm{O}_{\mathrm{s}} \mathrm{H}$ site. A DFT-based molecular dynamics simulation study of a water film on the pyrophyllite surface reported $\mathrm{H}$ bond distances of $1.78 \AA$ and $2.08 \AA$ for the $\mathrm{O}_{\text {sb }}$ site and $\mathrm{O}_{\mathrm{s}} \mathrm{H}$ site, respectively (Churakov, 
2007). Because the H-bond with $\mathrm{O}_{\mathrm{sb}}$ was much stronger than that with $\mathrm{O}_{\mathrm{s}} \mathrm{H}\left(H_{\mathrm{ads}}=61\right.$ vs. 25 $\mathrm{kJ} / \mathrm{mol}$, respectively), the $\mathrm{O}_{\mathrm{sb}}$ site is expected to be associated with the excess water prior to the $\mathrm{O}_{\mathrm{s}} \mathrm{H}$ site. The excess water molecules also formed an H-bond network with adsorbed water molecules and completed a water bridge across the dioctahedral vacancy exposed at the edge surface. The $\mathrm{H}$-bonded water molecule associated with the $\mathrm{O}_{\mathrm{sb}}$ site formed $\mathrm{H}$-bonds with $\equiv \mathrm{AlOH}_{2}$ (molecularly adsorbed water) and $\equiv \mathrm{O}_{\mathrm{s}} \mathrm{H} \ldots \mathrm{H}_{2} \mathrm{O}$ (H-bonded water to the $\mathrm{O}_{\mathrm{s}} \mathrm{H}$ site) at $\mathrm{H}$-bond distances of $1.7 \AA$ and $1.9-2.0 \AA$, respectively. At the $\mathrm{O}_{\mathrm{s}} \mathrm{H}$ site, the $\mathrm{H}$ bonded water formed additional $\mathrm{H}$-bonds with $\equiv \mathrm{Si}(2) \mathrm{OH}$ (dissociatively adsorbed water) and $\equiv \mathrm{AlOH}_{2}$ at about $2.4-2.5 \AA$. This H-bond network has been recently identified in a classical mechanical simulation of the pyrophyllite surface and postulated as a stabilizing mechanism for the disordered edge structures (Newton, 2012). On the other hand, the bridging $\mathrm{O}$ site $\left(\mathrm{O}_{\mathrm{sb}}\right)$ at the $\mathrm{B}$ edge surface is inaccessible to the additional water molecules; the B edge has fewer sites than AC edge that can form H-bonds with water vapor. Geometry optimizations of the initial $\mathrm{H}$-bond configurations between $\mathrm{H}_{2} \mathrm{O}$ and the $\mathrm{O}_{\text {sb }}$ site demonstrated that the extra water molecules formed a water network on the surface linking exposed neighboring aluminol group $\left(\equiv \mathrm{Al}-\mathrm{O}_{\mathrm{s}} \mathrm{H}\right.$ or $\left.\equiv \mathrm{Al}-\mathrm{OH}_{2}\right)$ and silanol groups with $\mathrm{H}$-bond distances of $1.5-$ $1.7 \AA$ and $2.2 \AA$, respectively. As previously discussed, we also found that the additional $\mathrm{H}_{2} \mathrm{O}$ molecules to the $\mathrm{B}$ edge surface $\left(\Theta=5.7 \mathrm{H}_{2} \mathrm{O} / \mathrm{nm}^{2}\right)$ lead to one of the surface $\mathrm{Al}$ being in five-fold coordination (Fig. 1f).

\subsection{Surface free energy and equilibrium morphology}

In the surface free-energy calculation, the Gibbs energy difference between the bulk and surface in equation (7) is frequently approximated by the total energy difference. This is a reasonable approach for pristine surfaces with no hydration because the vibrational energy 
difference between the bulk and surface is sufficiently small to be neglected. When the surface is hydrated, however, the vibrational contribution of the adsorbed water molecules $\left(\gamma^{\mathrm{vib}}\right)$ that is not present in the bulk can be significant to the surface free energy, and thus the vibrational energy difference cannot be ignored (Sun et al., 2003). We estimated $\gamma^{\text {vib }}$ for the edge surfaces at different surface coverages (Fig. S1). Overall, the $\gamma^{\text {vib }}(T)$ varied little whether water was bound to surface sites via dissociative, molecular or H-bond adsorption; the $\gamma^{\text {vib }}$ at $300 \mathrm{~K}$ was approximately $6 \mathrm{meV} / \AA^{2}\left(\sim 0.1 \mathrm{~J} / \mathrm{m}^{2}\right)$ per sorbed $\mathrm{H}_{2} \mathrm{O}$. For reference, the $\gamma^{\mathrm{vib}}$ of a hydrated $\mathrm{RuO}_{2}$ (110) surface was estimated to be $15 \mathrm{meV} / \AA^{2}$ per hydroxyl group at $T<700$ $\mathrm{K}$ (Sun et al., 2003); the $\gamma^{\text {vib }}$ of a forsterite (100) surface was calculated to be $8-18 \mathrm{meV} / \AA^{2}$ per sorbed water molecule at $300 \mathrm{~K}$ (Prigiobbe et al., 2013). In our case, the $\gamma^{\mathrm{vib}}$ of the AC and $\mathrm{B}$ edge surface at $\Theta \cong 2 \mathrm{H}_{2} \mathrm{O} / \mathrm{nm}^{2}(T=300 \mathrm{~K})$ was estimated to be 12 and $13 \mathrm{meV} / \AA^{2}$, respectively. These $\gamma^{\text {vib }}$ are similar in magnitude to the surface energies calculated by using the total energy difference at $0 \mathrm{~K}$ [i.e., surface excess energy, $\left(E_{\text {surf }}-4 E_{\text {bulk }}\right) / 2 A-\Theta \cdot E_{\mathrm{H} 2 \mathrm{O}}$ ]: the surface excess energies were 11.3 and $10.5 \mathrm{meV} / \AA^{2}$ for the $\mathrm{AC}$ and $\mathrm{B}$ edge surfaces, respectively (Table 2 ). At $\Theta \cong 4 \mathrm{H}_{2} \mathrm{O} / \mathrm{nm}^{2}(T=300 \mathrm{~K})$, the vibrational contribution was much greater than the surface excess energy: 24 vs. $-3.9 \mathrm{meV} / \AA^{2}$ for the AC edge surface and 25 vs. $3.0 \mathrm{meV} / \AA^{2}$ for the B edge surface, respectively. These results demonstrate that the vibrational contribution is not negligible to the surface free energy of hydrated pyrophyllite edge surfaces.

The stability of hydrated surfaces is a function of temperature and water vapor pressure (Fig. 4). As temperature increases, the hydrated surface free energies increase. A lower surface free energy indicates a more stable surface. In general, hydrated surfaces are more stable than dry surfaces. However, at the highest temperature considered, some 
hydrated surfaces became less stable than pristine surfaces (i.e., $\Theta=0 \mathrm{H}_{2} \mathrm{O} / \mathrm{nm}^{2}$ ). In contrast to the temperature effect, an increase in the chemical potential (or vapor pressure) of water leads to a decrease in the surface free energy of hydrated surfaces. The rate of surface free energy decrease with increasing water vapor pressure is greater at higher surface coverages as equation (7) makes evident. Thus, hydrated surfaces tend to have lower surface energies at higher partial pressures of water vapor. In dry conditions $\left(p_{H 2 O}<\sim 10^{-12} \mathrm{~atm}\right)$, the most stable AC edge surface had dissociated water molecules adsorbed to the Si surface sites (i.e., $\Theta=$ 1.9 $\mathrm{H}_{2} \mathrm{O} / \mathrm{nm}^{2}$ ). This surface has five-fold $\mathrm{Al}$ in a square-pyramidal configuration. This structure indicates the presence of a stable five-fold $\mathrm{Al}$ on the $\mathrm{AC}$ edge at low vapor pressures. The AC edge with $\Theta=3.9 \mathrm{H}_{2} \mathrm{O} / \mathrm{nm}^{2}$ was stable for a narrow range of water chemical potentials (i.e., $\Delta \mu_{\mathrm{H} 2 \mathrm{O}}=-0.65$ to $-0.59 \mathrm{eV}$ at $240 \mathrm{~K} ; \Delta \mu_{\mathrm{H} 2 \mathrm{O}}=-0.81$ to $-0.79 \mathrm{eV}$ at $600 \mathrm{~K}$ ) above which the surface of coverage $5.8 \mathrm{H}_{2} \mathrm{O} / \mathrm{nm}^{2}$ was the more stable edge surface. We note in passing that although the detailed ranges of chemical potential and temperature for a stable surface may be affected by the numerical accuracy of our calculated surface free energy, the overall trends in surface stability are unaffected by the uncertainties in our calculation.

At the saturation vapor pressure of water (vertical line in Fig. 4), the most stable B edge surface (dashed lines) possessed five-fold Al sites, whereas the most stable AC surface (solid lines) did not have a five-fold $\mathrm{Al}$ except at $600 \mathrm{~K}$. In the case of the B edge surfaces, the lower coverage surface $\left(\Theta=1.9 \mathrm{H}_{2} \mathrm{O} / \mathrm{nm}^{2}\right)$ was always more stable than the surface with the higher coverage surface $\left(\Theta=3.8 \mathrm{H}_{2} \mathrm{O} / \mathrm{nm}^{2}\right)$ at all temperatures examined. Thus, at the saturation vapor pressure, dissociated water molecules at the Si sites and five-fold trigonalbipyramidal Al sites are expected on the B edge surface regardless of temperature. In 
molecular dynamics simulation studies, a dynamic mixture was described between five- and six-fold coordination at the Al sites of the B edge interface (Liu et al., 2015; Newton and Sposito, 2015; Tazi et al., 2012). In the case of the AC edge surfaces, the surface with $\Theta=5.8$ $\mathrm{H}_{2} \mathrm{O} / \mathrm{nm}^{2}$ was most stable at 240,300 , and $400 \mathrm{~K}$. Thus, at the maximum chemical potential, the AC edge surface is expected to possess dissociated water to the Si sites, molecular adsorbed water to the $\mathrm{Al}$ site, and $\mathrm{H}$-bonded water to $\mathrm{O}_{\mathrm{sb}}$; surface $\mathrm{Al}$ sites are all six-fold coordinated on the AC edge surface. In contrast, the surface of coverage $1.9 \mathrm{H}_{2} \mathrm{O} / \mathrm{nm}^{2}$ was the most stable phase at $600 \mathrm{~K}$. At that temperature, H-bonded water and molecular adsorbed water would desorb from the surface leaving the $\mathrm{Al}$ sites in five-fold coordination as described in the previous section.

The relative stability between the $\mathrm{AC}$ and $\mathrm{B}$ edge surfaces changes with temperature and water vapor pressure. At low vapor pressures (dry conditions), both edge surfaces showed similar stabilities. At the saturation vapor pressure (humid conditions), however, the AC edge was more stable than the B edge surface except at $600 \mathrm{~K}$. At the highest temperature investigated, both surfaces showed similar stabilities under dry conditions as molecular adsorbed water desorbs from the surface. The surface stabilities also change with surface coverage because water adsorption greatly reduces the difference in the surface energies. For pristine surfaces $\left(\Theta=0 \mathrm{H}_{2} \mathrm{O} / \mathrm{nm}^{2}\right)$, the surface energy of the AC edge surface was lower than that of the $B$ edge by as much as $50 \mathrm{meV} / \AA^{2}$. At the low surface coverage $\left(\Theta \cong 2 \mathrm{H}_{2} \mathrm{O} / \mathrm{nm}^{2}\right)$, the surface energies were virtually identical (i.e., energies differed only by less than 0.3 meV/ $\left.\AA^{2}\right)$. However, at a higher surface coverage $\left(\Theta \cong 4 \mathrm{H}_{2} \mathrm{O} / \mathrm{nm}^{2}\right)$, the AC edge surface was more stable than the B edge by $6-8 \mathrm{meV} / \AA^{2}$ at a given temperature.

The equilibrium morphology of pyrophyllite crystals is also influenced by 
environmental conditions. The abundance and relative extent of exposed edge surfaces are determined by the magnitudes of surface energies that are, as we have demonstrated, a function of temperature and vapor pressure. In nature, pyrophyllite is observed as anhedral to subhedral platy crystals or sometimes as lath-like plates (Brindley and Wardle, 1970; Kitagawa et al., 1999). An electron microscopic study suggested that the morphology may be controlled by disorder in the sheet stacking structure (Kogure et al., 2006). Effects of the sheet stacking structure on the pyrophyllite morphology have not yet been explored with DFT studies. However, 2-D planar habits have been predicted through Wulff constructions (Wulff, 1901) based on calculated surface excess energies; euhedral crystals would take on a pseudohexagonal or rhombohedral shape depending on the surface coverage of water (Churakov, 2006; Lavikainen et al., 2015). Wulff constructions with our calculated surface free energies that include the vibrational component demonstrate that the equilibrium morphology of pyrophyllite crystals tend to be influenced by temperature and vapor pressure (Fig. 4a). Under conditions of low vapor pressures (region I in Fig. 4a), a pseudohexagonal shape is expected due to the equivalent surface energies of the $\mathrm{AC}$ and $\mathrm{B}$ edges (i.e., equivalent exposure of the two surfaces). Under conditions of high vapor pressures (region II in Fig. 4a), a rhombohedral planar shape is preferred with the AC edge surface being the most extensive because it possesses the lowest surface energy. As temperature increases, the vapor pressure range for region I and II changed significantly. At the highest temperature investigated $(600 \mathrm{~K})$, pyrophyllite crystals assume a pseudohexagonal planar shape even at the water saturation vapor pressure.

\section{DISCUSSIONS}




\subsection{Negative surface excess energies}

The calculated surface excess energies for the AC and B edge surfaces at different water surface coverages are summarized in Table 2 . The decrease in the excess energy with increasing surface coverage indicates that the pristine surface is gradually stabilized through the adsorption of water. The same trend was also reported in previous DFT studies of the pyrophyllite edges (Churakov, 2006; Martins et al., 2014). Churakov (2006) reported a decrease in the surface excess energy of the AC edge surface of $\sim 10 \mathrm{meV} / \AA^{2}$ when $\Theta$ increases from approximately 2 to $4 \mathrm{H}_{2} \mathrm{O} / \mathrm{nm}^{2}$ [i.e., 12.2 to $1.6( \pm 1) \mathrm{meV} / \AA^{2}$ ]. With the reported uncertainty in this previous calculation method, the surface excess energy of the AC edge at $\Theta \cong 4 \mathrm{H}_{2} \mathrm{O} / \mathrm{nm}^{2}$ is vanishingly small. Our calculation predicts that the surface excess energy becomes negative when the surface coverage is greater than or equal to 4 and 6 $\mathrm{H}_{2} \mathrm{O} / \mathrm{nm}^{2}$ for the AC and B edge surfaces, respectively (Table 2). Although no DFT simulations have reported a negative surface excess energy for the pyrophyllite edge, surface excess energy calculations with parameterized potentials have reported negative values (Bleam et al., 1993; Newton and Sposito, 2015).

Negative surface energies have generated some confusion in the past, but the misconception that the dissolution of the mineral must follow because there is no energetic cost to creating the surface has been previously addressed (Lodziana et al., 2005; Mathur et al., 2005). The reality of negative interfacial energies and thermodynamic conditions that enable them has been similarly demonstrated (Lin et al., 2006; Łodziana et al., 2004; Overbeek, 1978; Stol and DeBruyn, 1980). In our case, the negative surface excess energy of the pyrophyllite edges arises from the strong adsorption of water; the pristine surface is stabilized through this exothermic surface reaction. Because the vibrational energy 
contribution $\left(\gamma^{\mathrm{vib}}\right)$ counters the negative surface excess energy (i.e., creates a net positive free energy), $\gamma^{\text {vib }}$ can be identified as a destabilizing energetic term in the surface free energy to prevent dissolution. Thus, an accurate assessment of the pyrophyllite surface stability requires consideration of the vibrational energy from adsorbed water molecules.

\subsection{Structure and stability of EF defects}

The pyrophyllite bulk structure was geometry-optimized with the incorporation of three different EF defect ratios (Table 1). When the inverted structure was incorporated in the bulk structure (Fig. 2b), the $c$-axis increased considerably while the $a$-and $b$-axes remained similar to those of pure pyrophyllite. These are consistent trends regardless of whether the dispersion correction method was used (PBE or PBE-D). The much larger $c$-axis lattice parameter than the experimentally observed value for pyrophyllite may imply that the defect is not feasible in bulk pyrophyllite. However, we cannot exclude the possibility of the defect occurrence in montmorillonite. The EF model of 2:1 phyllosilicates was originally proposed for montmorillonite which includes hydrated cations in the interlayer (Edelman and Favejee, 1940; Grim, 1968). The pyrophyllite interlayer neither hydrates nor contains counter ions. Thus, the predicted change in the $c$-axis lattice parameter was pronounced in pyrophyllite, yet the change may be unnoticeable in structures where the hydrated interlayer space is sufficient to accommodate inverted Si-tetrahedra. In the interlayer, the inverted Si was displaced from the atomic plane of the other Si by $1.24 \AA$. The apical $\mathrm{OH}$ bonded to the inverted $\mathrm{Si}$ tetrahedron formed an H-bond with the basal O of a neighboring 2:1 layer at $1.96 \AA$ $\left(\equiv \mathrm{SiOH} \ldots \mathrm{O}_{\text {basal }}\right)$. The $\mathrm{Si}$ inversion creates an undercoordinated $\mathrm{O}$ that is saturated by a proton (Fig. 2b). This proton was directed toward the center of the dioctahedral vacancy and was separated from the extant structural hydroxyl group of the octahedral sheet by a distance of 
$2.25 \AA$. This $\mathrm{H}$ configuration at the dioctahedral vacancy site is similar to the $\mathrm{H}$ configuration of the Ruetchi defect that occurs in phyllomangates (Ruetschi, 1984). At the Ruetschi defect, a missing Mn(IV) cation is compensated by four protons; at this EF defect, three protons are present in the dioctahedral vacancy. If the EF defects are present on exposed basal planes,

The free energy difference for the EF-defect incorporation reaction $\left(\Delta G_{\mathrm{EF}}\right)$ remained positive under the conditions we examined here (solid lines in Fig. 5). Although computational errors are considered in the range of $\Delta G_{\mathrm{EF}}$ and $\Delta \mu_{\mathrm{H} 2 \mathrm{O}}$, the formation of EF defects in the pyrophyllite bulk structure appears to be unfavorable when they are at equilibrium with water vapor. However, $\Delta G_{\mathrm{EF}}$ decreased with increasing water chemical potential and decreasing defect ratio. If the EF defect does occur in montmorillonite, the defects may exist as low-density crystal defects rather than the revised lattice structure with $20 \%$ Si-inversion that was proposed for the montmorillonite structure by Edelman and Favejee (1940). If the defects are present on the exposed siloxane basal planes, the additional hydroxyl groups associated with these defects may lead to the basal surface being more reactive to water adsorption.

The importance of the vibrational contribution in the evaluation of thermodynamic stability is apparent in Fig. 5. When the free energy was replaced by total energy at $0 \mathrm{~K}$ (i.e., $G \approx E^{\mathrm{tot}}$ ) (dashed lines in Fig. 5), the formation of the EF defect structure becomes favorable as the water chemical potential approaches the saturation vapor pressure at $300 \mathrm{~K}$ and $400 \mathrm{~K}$. This interpretation contradicts the more rigorous free-energy calculation that considered the vibrational energies (solid lines in Fig. 5). Alternatively, the reaction feasibility may be evaluated by using a single value for the total energy for water $\left(E_{\mathrm{H} 2 \mathrm{O}}\right)$ [i.e., 
$\left.\Delta G_{\mathrm{EF}} \approx\left(E_{E F}^{t o t}-\frac{N_{\mathrm{Al}}}{4} E_{p y r o}^{\text {tot }}\right)-\frac{N_{\mathrm{Al}}}{4} m E_{\mathrm{H}_{2} \mathrm{O}}^{\text {tot }}\right]$ in equation (10). Unfortunately, this approach also leads to an erroneous conclusion because the reaction energy was negative for all of the EF defect ratios examined. The approximate $\Delta G_{\mathrm{EF}}$ values were $-16,-70$ and $-160 \mathrm{meV} / \mathrm{f} . \mathrm{u}$. at defect ratios of $0.03,0.125$ and 0.25 , respectively.

The EF defect was incorporated at the AC edge surface with coverage of 3.9 $\mathrm{H}_{2} \mathrm{O} / \mathrm{nm}^{2}$. The initial configuration of the EF defect possessed an $\mathrm{Si}(1)$ tetrahedron rotated 90 degrees toward the neighboring 2:1 layer. With this rotation, three distinct features at the edge were i) a $\equiv \mathrm{Si}-\mathrm{OH}$ group directed perpendicular to the basal plane; ii) an undersaturated $\mathrm{O}_{\mathrm{sb}}$ in the plane of the basal $\mathrm{O}$; and iii) an edge $\mathrm{Al}$ with a five-fold, square pyramidal coordination. After geometry optimization (Fig. 6), the $\mathrm{O}_{\text {sb }}$ became saturated via a proton transfer from the $\mathrm{H}_{2} \mathrm{O}$ that is molecularly adsorbed to the $\mathrm{Al}$ site (i.e., $\equiv \mathrm{Al}-\mathrm{OH}_{2}+\equiv \mathrm{Si}-\mathrm{O}_{\mathrm{sb}} \rightarrow \equiv \mathrm{Al}-\mathrm{OH}+\equiv \mathrm{Si}-$ $\mathrm{O}_{\mathrm{sb}} \mathrm{H}$ ). The five-fold $\mathrm{Al}$ site subsequently rearranges to a trigonal bypyramidal coordination. The $d\left(\mathrm{Al}-\mathrm{OH}_{2}\right)$ was $2.04 \AA$ on the surface without the EF defect. After the H-transfer at the EF defect, the corresponding $d(\mathrm{Al}-\mathrm{OH})$ of the five-fold $\mathrm{Al}$ site was $1.77 \AA$, and the $\equiv \mathrm{Al}-\mathrm{OH}$ group was nearly parallel to the $\mathrm{Al}$ atomic plane. This $d(\mathrm{Al}-\mathrm{OH})$ agrees with the distances predicted by quantum chemical calculations of hydrolyzed Al clusters (Kubicki, 2001; Miao et al., 2004). The five-fold Al site becomes six-fold coordinated when an additional water molecule binds to the site (i.e., AC edge surface with $\Theta=4.8 \mathrm{H}_{2} \mathrm{O} / \mathrm{nm}^{2}$ ). The $\mathrm{Si}(1)$ of the EF defect was positioned $\sim 0.8 \AA$ from the Si atomic plane of the tetrahedral sheet (Fig. 6). The apical hydroxyl of the inverted $\mathrm{Si}(1)$ formed a strong H-bond (1.8 $)$ with silanols of the adjacent layer. In swelling 2:1 phyllosilicates such as montmorillonite, this inverted configuration linking adjacent layers might affect the sorption reactivity at the edge sites and the diffusion of ions and water into the interlayer region. 
The stability of the defective edge surface was evaluated at two different defect ratios (inverted $\mathrm{Si}$ : total edge surface $\mathrm{Si}=0.25$ and 0.125 ) when the bulk and edge surface are at equilibrium with water vapor (Fig. 7). The difference between the lower-defective and nondefective surface energies was $1-3 \mathrm{meV} / \AA^{2}$ at the same coverage of the AC edge surface $\left(\Theta=3.9\right.$ or $\left.5.8 \mathrm{H}_{2} \mathrm{O} / \mathrm{nm}^{2}\right)$, which is within the energy difference between the most stable defect-free AC and B edge surfaces near the saturation vapor pressure. The lower defect ratio also possessed a lower surface energy than the defect-free B edge surface at the same coverage. At $240 \mathrm{~K}$ and $300 \mathrm{~K}$, the $\mathrm{AC}$ edge with the lower defect ratio $\left(\mathrm{EF}_{0.125}\right)$ showed a lower surface energy than the $\mathrm{B}$ edge surface with coverage $1.9 \mathrm{H}_{2} \mathrm{O} / \mathrm{nm}^{2}$ at the saturation vapor pressure. Thus, the metastable EF defect on the AC edge surfaces is plausible under thermodynamic conditions when the B edge surface would be exposed. Under conditions in which the most stable surface is the AC edge surface $\left(\Theta=3.9 \mathrm{H}_{2} \mathrm{O} / \mathrm{nm}^{2}\right)$, a rhombohedral planar shape is preferred (region II in Fig. 4a). A range of water chemical potential below saturation exists where the incorporation of the EF defect onto the AC edge destabilizes the edge surface. In this range (e.g., $\Delta \mu_{\mathrm{H} 2 \mathrm{O}} \approx-0.7 \sim-0.6 \mathrm{eV}$ at $240 \mathrm{~K}$ and $300 \mathrm{~K}$ ), the $\mathrm{B}$ edge surface $\left(\Theta=1.9 \mathrm{H}_{2} \mathrm{O} / \mathrm{nm}^{2}\right)$ becomes more stable than the defected AC surface. At these water chemical potentials and with the incorporation of the EF defects, the equilibrium morphology of pyrophyllite would tend toward a more pseudohexagonal shape. Thus, one can infer from these surface free energy calculations that the crystal morphology is also influenced by surface defects at the edges.

\section{CONCLUSIONS}

We have examined the effects of temperature and humidity on the structure and 
thermodynamic stability of the pyrophyllite AC and B edge surfaces. The stability of a dry pristine edge surface, which has unfavorable dangling bonds and undersaturated atoms, is greatly stabilized through the dissociative, molecular, or H-bond adsorption of water. Hydrated surfaces had very small or even negative surface excess energies due to the strong exothermic adsorption processes. Whereas a negative surface excess energy is counterintuitive, we found that the negative excess energy is destabilized by the vibrational contribution of water molecules sorbed to the surface; the vibrational energy is much greater than the surface excess energy and leads to a net positive surface free energy. This analysis demonstrates the importance of the thermal vibrational contribution of surfaces when assessing surface stabilities of clay minerals. To our knowledge, these reported surface free energies for the pyrophyllite edge are the first to be calculated as a function of temperature and water chemical potential ( $T$ and $\mu_{\mathrm{H} 2 \mathrm{O}}$ ). In general, the AC edge surface is more stable than the B edge surface, but the stabilities strongly depend on these two environmental variables. Hence, the equilibrium morphology exposed by the two edge surfaces is also a function of the environmental conditions. Under conditions of ice nucleation (e.g., low $T$ and high $p_{\mathrm{H} 2 \mathrm{O}}$ ), the AC edge surface is expected to be a dominant edge surface. Thus our results further postulate that the AC edge surface is a possible ice nucleation site of 2:1 clay minerals. Conclusive proof has not yet been provided for the presence of the EF surface defect, but the energetic comparison does not preclude its existence at the surface of this highly anisotropic mineral. Because the EF defects provide additional hydroxyl groups to the surface, such defects may modify the surface reactivity toward interaction with water, an important insight in identification of ice nucleation sites. Our detailed surface structure with water vapor and thermodynamics data should provide basic knowledge to identification of ice nucleation sites and molecular-level characterization of surface interactions with trace gases 
which may impact the ice nucleation reactivity of clay minerals.

\section{ACKNOWLEDGEMENTS}

This research was supported by Basic Science Research Program through the National Research Foundation of Korea (NRF) funded by the Ministry of Science, ICT and Future Planning (NRF-2013R1A1A1004657 and NRF-2015R1A4A1041105). Part of the computations were performed using resources of the National Energy Research Scientific Computing Center, which is supported by the Office of Science of the U.S. Department of Energy under Contract No. DE-AC02-05CH11231.

\section{APPENDIX A. SUPPLEMENTARY DATA}

Supplementary data associated with this article can be found, in the online version, at http://dx.doi.org/xxx.

\section{REFERENCES}

Ackland G. J., Warren M. C. and Clark S. J. (1997) Practical methods in ab initio lattice dynamics. J. Phys. Condens. Matter 9, 7861.

Barzilai J. and Borwein J. M. (1988) Two-point step size gradient methods. IMA J. Numer. Anal. 8, 141-148.

Bickmore B. R., Rosso K. M., Nagy K. L., Cygan R. T. and Tadanier C. J. (2003) Ab initio determination of edge surface structures for dioctahedral 2 : 1 phyllosilicates: Implications for acid-base reactivity. Clay. Clay Miner. 51, 359-371.

Bleam W. F., Welhouse G. J. and Janowiak M. A. (1993) The surface Coulomb energy and proton Coulomb potentials of pyrophyllite $\{010\},\{110\},\{100\}$, and $\{130\}$ edges. Clay. Clay Miner. 41, 305-316.

Brindley G. W. and Wardle R. (1970) Monoclinic and triclinic forms of pyrophyllite and pyrophyllite anhydride. Am. Mineral. 55, 1259-1272.

Chase M. W., (1998) NIST-JANAF Thermochemical Tables, 4th ed. American Chemical Society, Washington, D.C.

Churakov S. V. (2006) Ab initio study of sorption on pyrophyllite: Structure and acidity of the edge sites. J. Phys. Chem. B 110, 4135-4146.

Churakov S. V. (2007) Structure and dynamics of the water films confined between edges of pyrophyllite: A first principle study. Geochim. Cosmochim. Acta 71, 1130-1144.

Clark S. J., Segall M. D., Pickard C. J., Hasnip P. J., Probert M. J., Refson K. and Payne M. C. (2005) First principles methods using CASTEP. Z. Kristallogr. 220, 567-570. 
Cox S. J., Raza Z., Kathmann S. M., Slater B. and Michaelides A. (2013) The microscopic features of heterogeneous ice nucleation may affect the macroscopic morphology of atmospheric ice crystals. Faraday Discuss. 167, 389-403.

Croteau T., Bertram A. K. and Patey G. N. (2009) Simulation of water adsorption on kaolinite under atmospheric conditions. J. Phys. Chem. A 113, 7826-7833.

Croteau T., Bertram A. K. and Patey G. N. (2010) Water adsorption on kaolinite surfaces containing trenches. J. Chem. Phys. A 114, 2171-2178.

Drits V. A., Derkowski A. and McCarty D. K. (2011) Kinetics of thermal transformation of partially dehydroxylated pyrophyllite. Am. Mineral. 96, 1054-1069.

Edelman C. H. and Favejee J. C. L. (1940) On the crystal structure of montmorillonite and halloysite. Z. Kristallogr. A102, 417-431.

Forster P., Ramaswamy V., Artaxo P., Berntsen T., Betts R., Fahey D. W., Haywood J., Lean J., Lowe D. C., Myhre G., Nganga J., Prinn R., Raga G., Schulz M. and Dorland R. V., (2007) Changes in Atmospheric Constituents and in Radiative Forcing, in: Solomon, S., Qin, D., Manning, M., Chen, Z., Marquis, M., Averyt, K.B., M.Tignor, Miller, H.L. (Eds.), Climate Change 2007: The Physical Science Basis. Contribution of Working Group I to the Fourth Assessment Report of the Intergovernmental Panel on Climate Change. Cambridge University Press, Cambridge, United Kingdom and New York, NY, USA.

Francis G. P. and Payne M. C. (1990) Finite basis set corrections to total energy pseudopotential calculations. J. Phys. Condens. Matter 2, 4395-4404.

Freedman M. A. (2015) Potential sites for ice nucleation on aluminosilicate clay minerals and related materials. J. Phys. Chem. Lett. 6, 3850-3858.

Grim R. E., (1968) Clay Mineralogy, 2nd ed. McGraw-Hill, New York.

Grimme S. (2006) Semiempirical GGA-type density functional constructed with a long-range dispersion correction. J. Comput. Chem. 27, 1787-1799.

Hartman P., (1973) Structure and morphology, in: Hartman, P. (Ed.), Crystal Growth: An Introduction North-Holland Publishing, Amsterdam, pp. 367-402.

Heller L., Farmer V., Mackenzie R., Mitchell B. and Taylor H. (1962) The dehydroxylation and rehydroxylation of triphormic dioctahedral clay minerals. Clay Minerals Bulletin 5, 5672.

Hoose C., Lohmann U., Erdin R. and Tegen I. (2008) The global influence of dust mineralogical composition on heterogeneous ice nucleation in mixed-phase clouds. Environ. Res. Lett. 3, 025003.

Hoose C. and Möhler O. (2012) Heterogeneous ice nucleation on atmospheric aerosols: a review of results from laboratory experiments. Atmos. Chem. Phys. 12, 9817-9854.

Hu X. L. and Michaelides A. (2007) Ice formation on kaolinite: Lattice match or amphoterism? Surf. Sci. 601, 5378-5381.

Jeong G. Y. and Achterberg E. P. (2014) Chemistry and mineralogy of clay minerals in Asian and Saharan dusts and the implications for iron supply to the oceans. Atmos. Chem. Phys. 14, 12415-12428.

Keren R. and Sparks D. (1995) The role of edge surfaces in flocculation of 2: 1 clay minerals. Soil Sci. Soc. Am. J. 59, 430-435.

Kitagawa R., Nishido H., Hwang J.-Y. and Yang P. (1999) Geochronological study of pyrophyllite deposits in East Asia. Resource Geology 20, 123-128.

Kogure T., Jige M., Kameda J., Yamagishi A., Miyawaki R. and Kitagawa R. (2006) Stacking structures in pyrophyllite revealed by high-resolution transmission electron microscopy 
(HRTEM). Am. Mineral. 91, 1293-1299.

Kremleva A., Martorell B., Kruger S. and Rösch N. (2012) Uranyl adsorption on solvated edge surfaces of pyrophyllite: a DFT model study. Phys. Chem. Chem. Phys. 14, 5815-5823.

Kubicki J. D. (2001) Self-consistent reaction field calculations of aqueous $\mathrm{Al}^{3+}, \mathrm{Fe}^{3+}$, and $\mathrm{Si}^{4+}$ : Calculated aqueous-phase deprotonation energies correlated with experimental $\ln \left(K_{\mathrm{a}}\right)$ and $\mathrm{p} K_{\mathrm{a} .} . J$. Phys. Chem. A 105, 8756-8762.

Lamb D. and Verlinde J., (2011) Physics and Chemistry of Clouds. Cambridge University Press, New York.

Lavikainen L., Hirvi J., Kasa S., Schatz T. and Pakkanen T. (2015) Stability of dioctahedral 2:1 phyllosilicate edge structures based on pyrophyllite models. Theor. Chem. Acc. 134, 18.

Lee J. H. and Guggenheim S. (1981) Single crystal X-ray refinement of pyrophyllite-1Tc. Am. Mineral. 66, 350-357.

Lin Z., Gilbert B., Liu Q. L., Ren G. Q. and Huang F. (2006) A thermodynamically stable nanophase material. J. Am. Chem. Soc. 128, 6126-6131.

Liu X. D., Cheng J., Sprik M., Lu X. C. and Wang R. C. (2014) Surface acidity of 2:1-type dioctahedral clay minerals from first principles molecular dynamics simulations. Geochim. Cosmochim. Acta 140, 410-417.

Liu X. D., Lu X. C., Cheng J., Sprik M. and Wang R. C. (2015) Temperature dependence of interfacial structures and acidity of clay edge surfaces. Geochim. Cosmochim. Acta $\mathbf{1 6 0}$, 91-99.

Łodziana Z., Tøpsoe N. Y. and Norskøv J. K. (2004) A negative surface energy for alumina. Nat. Mater. 3, 289-293.

Lodziana Z., Topsoe N.-Y. and Norskov J. K. (2005) Authors' response: Negative surface energy [mdash] clearing up confusion. Nat. Mater. 4, 186-186.

Martins D. M. S., Molinari M., Goncalves M. A., Mirao J. P. and Parker S. C. (2014) Toward modeling clay mineral nanoparticles: The edge surfaces of pyrophyllite and their interaction with water. J. Phys. Chem. C 118, 27308-27317.

Mathur A., Sharma P. and Cammarata R. C. (2005) Negative surface energy - Clearing up confusion. Nat. Mater. 4, 186.

Miao Q., Cao Q. and Bi S. (2004) Density functional theory study on the bridge structure in dimeric aluminum (III) water complexes. J. Chem. Phys. 121, 4650-4656.

Monkhorst H. J. and Pack J. D. (1976) Special points for Brillouin-zone integrations. Phys. Rev. B 13, 5188-5192.

Newton A. (2012) Atomistic Simulations of the Dioctahedral 2:1 Phyllosilicate Edge--Water Interface: Structure, Dynamic Properties, and Cation Complexes. Ph.D thesis, University of California.

Newton A. G. and Sposito G. (2015) Molecular Dynamics Simulations of Pyrophyllite Edge Surfaces: Structure, Surface Energies, and Solvent Accessibility. Clay. Clay Miner. 65, 278-290.

Overbeek J. T. G. (1978) Microemulsions, a Field at the Border between Lyophobic and Lyophilic Colloids. Faraday Discuss. 65, 7-19.

Perdew J. P., Burke K. and Ernzerhof M. (1996) Generalized gradient approximation made simple. Phys. Rev. Lett. 77, 3865-3868.

Prigiobbe V., Suarez Negreira A. and Wilcox J. (2013) Interaction between olivine and water based on density functional theory calculations. The Journal of Physical Chemistry C 117, 21203-21216. 
Pruppacher H. R. and Klett J. D., (1997) Microphysics of Clouds and Precipitation. Kluwer Academic Publishers, Boston, MA.

Pusch R. and Karnland O. (1996) Physico chemical stability of smectite clays. Eng Geol 41, 73-85.

Reuter K. and Scheffler M. (2001) Composition, structure, and stability of $\mathrm{RuO}_{2}$ (110) as a function of oxygen pressure. Phys. Rev. B 65, 035406.

Rogal J. and Reuter K., (2007) Ab initio atomistic thermodynamics for surfaces: A primer, Experiment, Modeling and Simulation of Gas-Surface Interactions for Reactive Flows in Hypersonic Flights. Educational Notes RTO-EN-AVT-142, Neuilly-sur-Seine, France, pp. 2.1-2.18.

Ruetschi P. (1984) Cation-vacancy model for $\mathrm{MnO}_{2}$. J. Electrochem. Soc. 131, 2737-2744.

Schuttlefield J. D., Cox D. and Grassian V. H. (2007) An investigation of water uptake on clays minerals using ATR-FTIR spectroscopy coupled with quartz crystal microbalance measurements. J. Geophys. Res. Atmos. 112, D21303.

Stol R. J. and DeBruyn P. L. (1980) Thermodynamic stabilization of colloids. J. Colloid Interface Sci. 75, 185-198.

Storelvmo T., Kristjánsson J. E. and Lohmann U. (2008) Aerosol influence on mixed-phase clouds in CAM-Oslo. J. Atmos. Sci. 65, 3214-3230.

Sun Q., Reuter K. and Scheffler M. (2003) Effect of a humid environment on the surface structure of $\mathrm{RuO}_{2}$ (110). Phys. Rev. B 67, 205424.

Suter J. L., Kabalan L., Khader M. and Coveney P. V. (2015) Ab initio molecular dynamics study of the interlayer and micropore structure of aqueous montmorillonite clays. Geochim. Cosmochim. Acta 169, 17-29.

Tang M., Cziczo D. J. and Grassian V. H. (2016) Interactions of water with mineral dust aerosol: Water adsorption, hygroscopicity, cloud condensation, and ice nucleation. Chem. Rev. 116, 4205-4259.

Tazi S., Rotenberg B., Salanne M., Sprik M. and Sulpizi M. (2012) Absolute acidity of clay edge sites from ab-initio simulations. Geochim. Cosmochim. Acta 94, 1-11.

Tunega D., Bučko T. and Zaoui A. (2012) Assessment of ten DFT methods in predicting structures of sheet silicates: Importance of dispersion corrections. J. Chem. Phys. 137, 114105.

Vanderbilt D. (1990) Soft self-consistent pseudopotentials in a generalized eigenvalue formalism. Phys. Rev. B 41, 7892-7895.

Voora V. K., Al-Saidi W. A. and Jordan K. D. (2011) Density functional theory study of pyrophyllite and $\mathrm{M}$-montmorillonites $(\mathrm{M}=\mathrm{Li}, \mathrm{Na}, \mathrm{K}, \mathrm{Mg}$, and $\mathrm{Ca})$ : Role of dispersion interactions. J. Chem. Phys. A 115, 9695-9703.

Welti A., Kanji Z. A., Lüönd F., Stetzer O. and Lohmann U. (2014) Exploring the mechanisms of ice nucleation on kaolinite: From deposition nucleation to condensation freezing. $J$. Atmos. Sci. 71, 16-36.

White G. N. and Zelazny L. W. (1988) Analysis and implications of the edge structure of dioctahedral phyllosilicates. Clay. Clay Miner. 36, 141-146.

Wulff G. (1901) On the question of speed of growth and dissolution of crystal surface. $Z$. Krystallogr. Minera. 34, 449.

Yongheng Z. and Zhenan G. (2006) The study of removing hydroxyl from silica glass. J. NonCryst. Solids 352, 4030-4033.

Zucker R. V., Chatain D., Dahmen U., Hagege S. and Carter W. C. (2012) New software tools for the calculation and display of isolated and attached interfacial-energy minimizing 
particle shapes. J. Mater. Sci. 47, 8290-8302.

Table 1. Lattice parameters of defect-free and defected pyrophyllite optimized using DFT without $(\mathrm{PBE})$ and with dispersion corrections (PBE-D).

\begin{tabular}{rrccrrrrrr}
\hline & & $0^{\mathrm{a}}$ & \multicolumn{2}{c}{$0.03^{\mathrm{a}}$} & \multicolumn{2}{c}{$0.125^{\mathrm{a}}$} & \multicolumn{2}{c}{$0.25^{\mathrm{a}}$} \\
& \multicolumn{1}{c}{ PBE } & PBE-D & Exp $^{\mathrm{b}}$ & \multicolumn{1}{c}{ PBE } & PBE-D & \multicolumn{1}{c}{ PBE } & PBE-D & \multicolumn{1}{c}{ PBE } & PBE-D \\
\hline$a(\AA)$ & 5.202 & 5.160 & 5.160 & 5.200 & 5.169 & 5.184 & 5.150 & 5.171 & 5.127 \\
$b(\AA)$ & 9.039 & 8.963 & 8.966 & 9.034 & 8.953 & 8.993 & 8.924 & 8.954 & 8.825 \\
$c(\AA)$ & 10.116 & 9.341 & 9.347 & 11.890 & 10.527 & 11.860 & 11.423 & 12.656 & 11.836 \\
\hline
\end{tabular}

${ }^{a}$ Defect ratio (the number of inverted $\mathrm{Si}$ : the number of possible $\mathrm{Si}$ inversions).

${ }^{\mathrm{b}}$ Experimental results (Lee and Guggenheim, 1981). 
Table 2. Surface excess energies (in $m e V / \AA^{2}$ ) of pyrophyllite edge surfaces at different surface coverages $\left(\Theta\right.$, in $\left.\mathrm{H}_{2} \mathrm{O} / \mathrm{nm}^{2}\right)$. The vibrational contribution of water adsorbates to the surface free energy (in meV/ $\AA^{2}$ ) estimated at $300 \mathrm{~K}$ is provided in parenthesis. n.r., not reported.

\begin{tabular}{ccccc}
\hline \multirow{2}{*}{} & \multicolumn{2}{c}{ Current DFT study } & \multicolumn{2}{c}{ Previous DFT study } \\
\cline { 2 - 5 } & AC edge & \multicolumn{1}{c}{ B edge } & AC edge & B edge \\
\hline 0 & $63.3(0.0)$ & $112.1(0.0)$ & n.r. & n.r. \\
2 & $11.3(11.6)$ & $10.5(12.2)$ & 12.2 & 11.8 \\
4 & $-3.9(24.7)$ & $3.0(24.8)$ & 1.6 & 5.4 \\
6 & $-16.3(36.2)$ & $-9.8(36.1)$ & n.r. & n.r. \\
\hline
\end{tabular}

${ }^{a}$ Churakov (2006). 
Figure 1. Pyrophyllite edge surface models. (a) Pristine AC edge before geometry optimization; (b) geometry-optimized pristine AC edge; (c) geometry-optimized hydrated AC edge surface (water coverage $=7.7 \mathrm{H}_{2} \mathrm{O} / \mathrm{nm}^{2}$ ); (d) pristine $\mathrm{B}$ edge before geometry optimization; (e) geometry-optimized pristine B edge; and (f) geometry-optimized hydrated B edge surface (water coverage $=5.7 \mathrm{H}_{2} \mathrm{O} / \mathrm{nm}^{2}$ ). Dotted circles identify the sites for dissociative adsorption of water; solid circles identify the sites for molecular adsorption of water. Color scheme: red = O; white $=\mathrm{H}$; magenta $=\mathrm{Al}$; ochre $=\mathrm{Si}$.

(a)

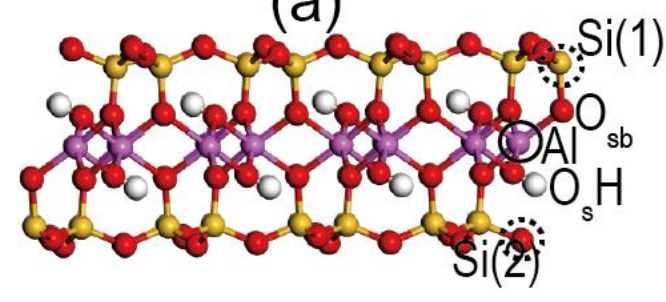

(b)

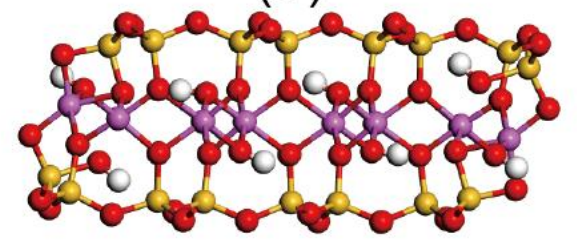

(c)

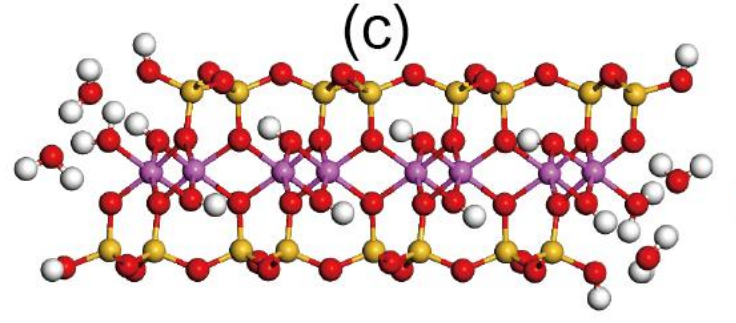

(d)

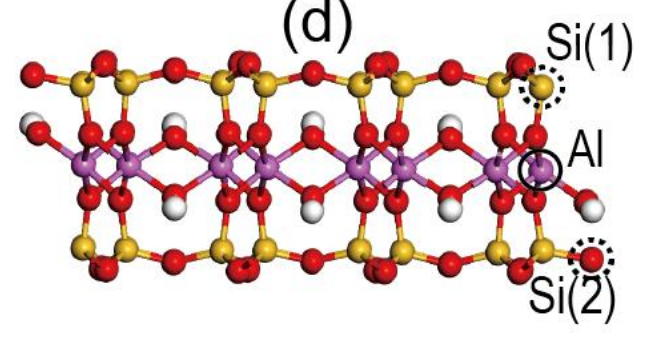

(e)

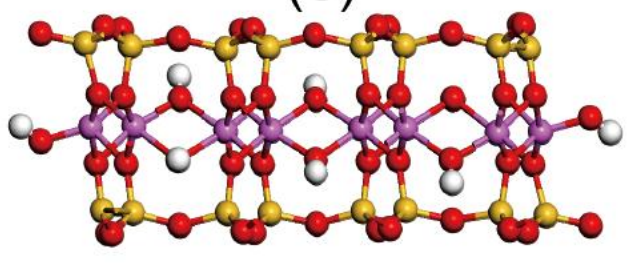

(f)

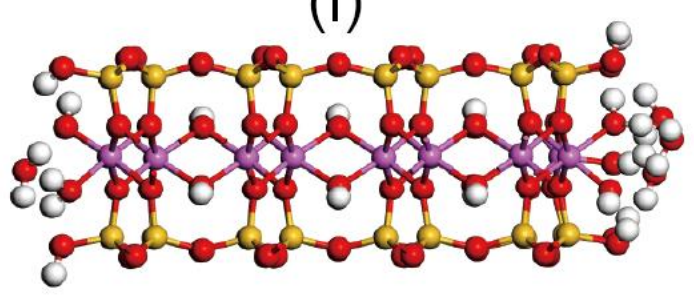


Figure 2. Perspective view of pyrophyllite interlayer (a) without and (b) with a Si cation vacancy defect $(\mathrm{EF}$ defect $)$. Color scheme: red $=\mathrm{O}$; white $=\mathrm{H}$; magenta $=\mathrm{Al}$; ochre $=\mathrm{Si}$.

(a)
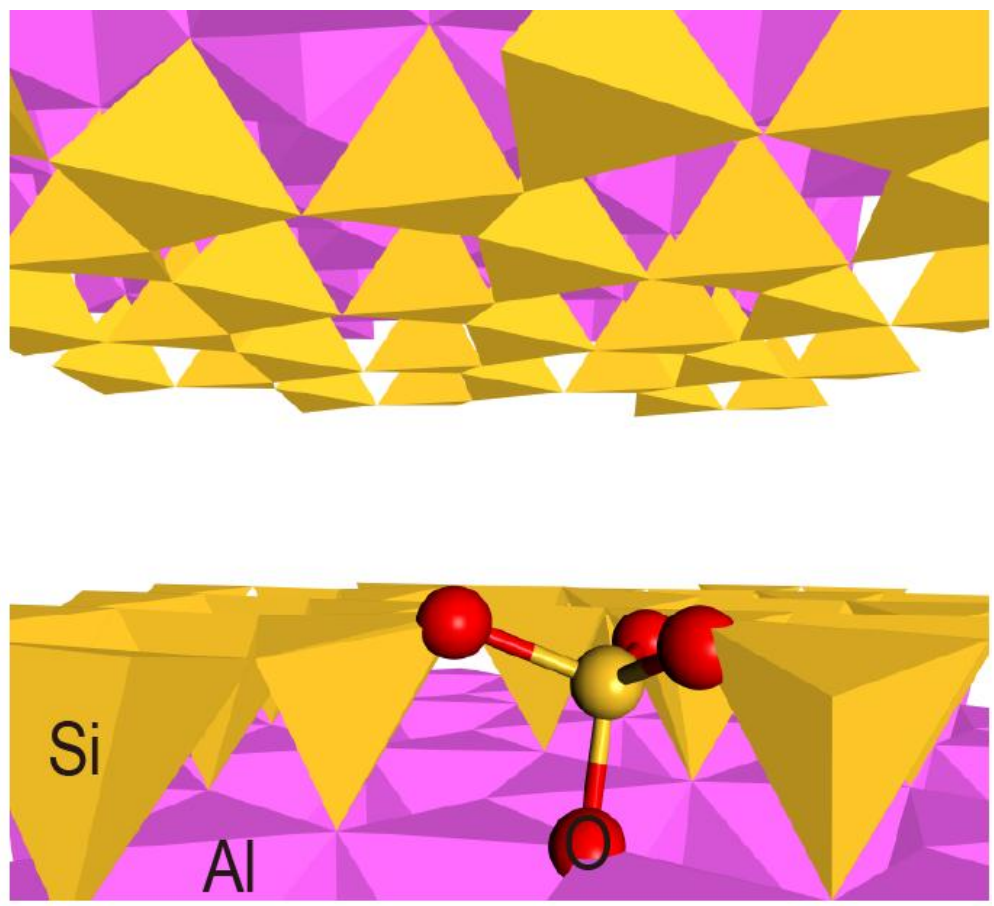

(b)

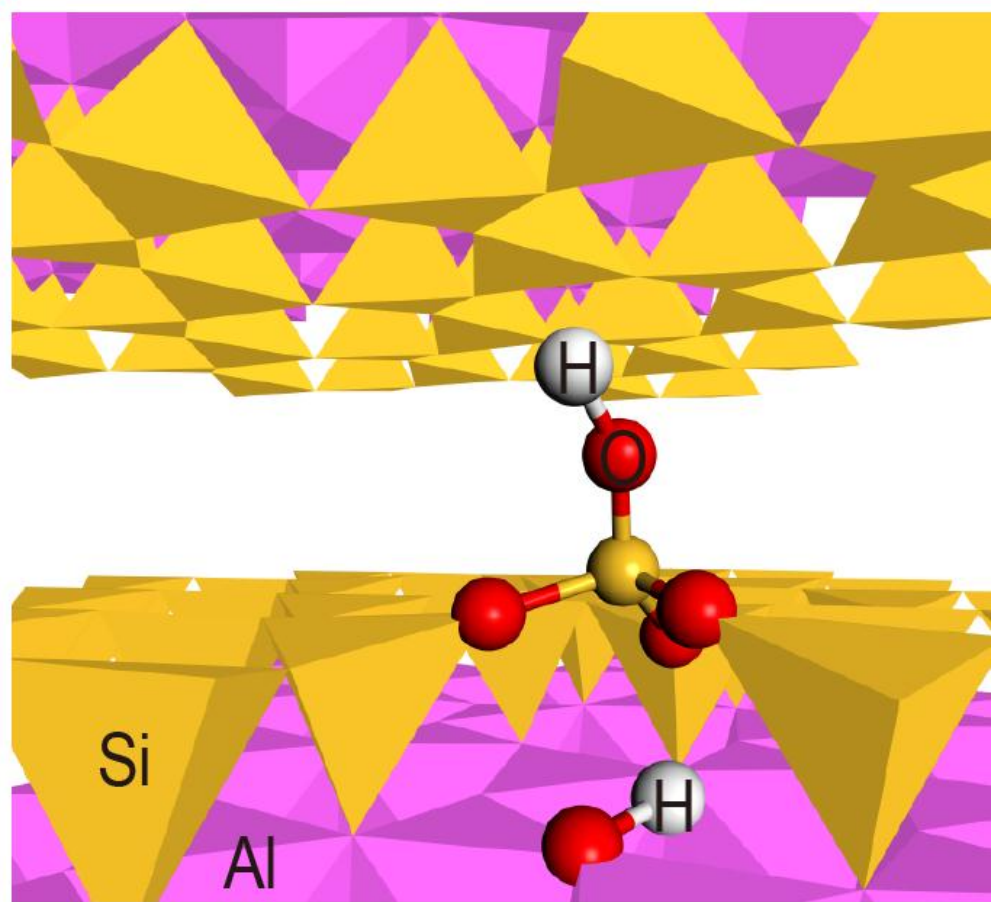


Figure 3. Differential adsorption energy of water on the AC (closed circle) and B (empty square) edge surface of pyrophyllite. Dissociative, molecular, and H-bond adsorption occurs at approximately $1-2,3-4$, and $5-8 \mathrm{H}_{2} \mathrm{O} / \mathrm{nm}^{2}$, respectively. Solid and dotted curves serve as a guide for the eye only.

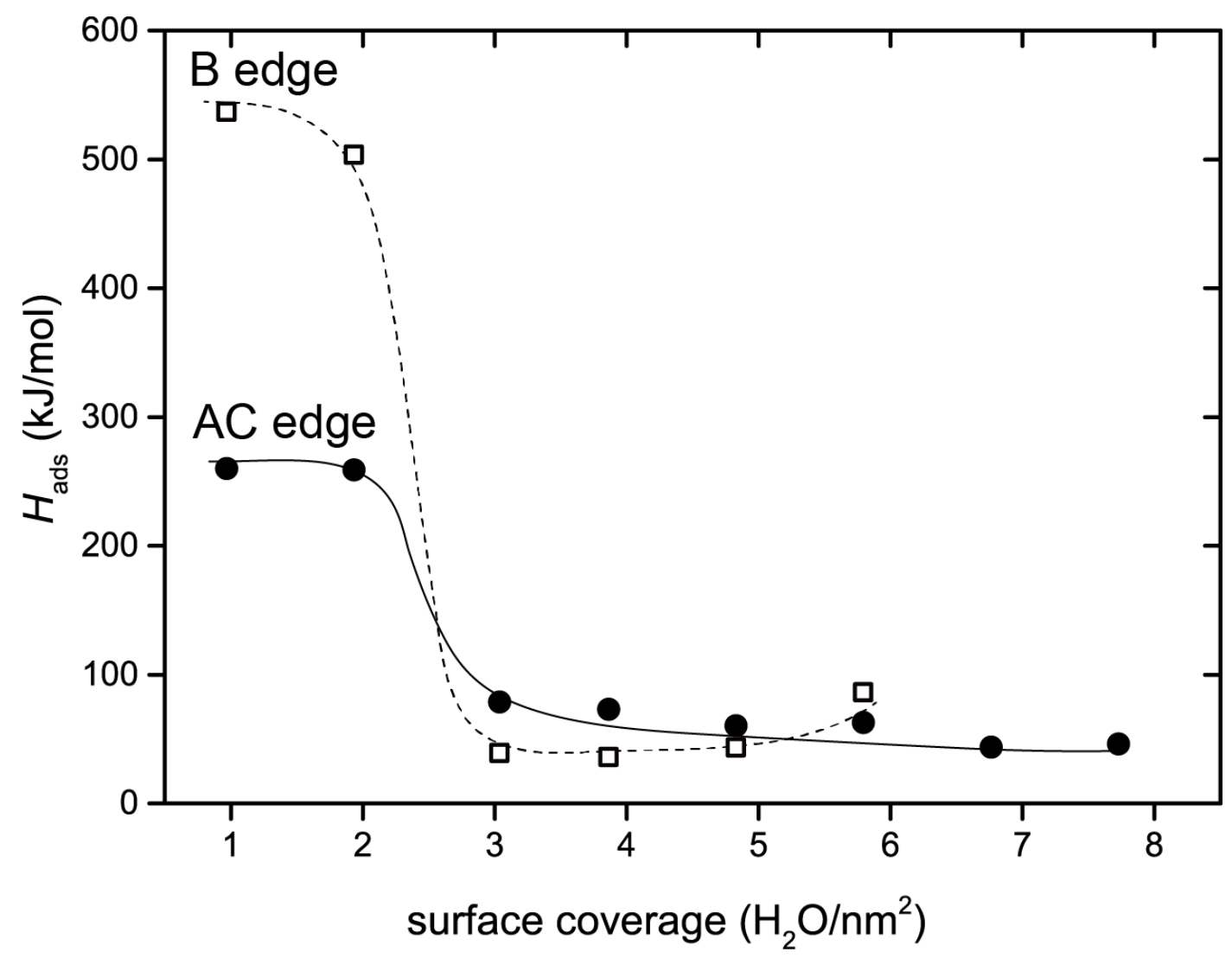


Figure 4. Surface free energies of pyrophyllite edges as a function of water chemical potential $(\Delta \mu)$ at (a) $240 \mathrm{~K}$, (b) $300 \mathrm{~K}$, (c) $400 \mathrm{~K}$, and (d) $600 \mathrm{~K}$. The partial pressure scale corresponding to the water chemical potential is provided on the top horizontal axis $\left(p^{0}=1 \mathrm{~atm}\right)$. Solid blue lines = AC edges; dashed orange lines $=\mathrm{B}$ edges; $\Theta=$ water coverage $\left(\right.$ in $\mathrm{H}_{2} \mathrm{O} / \mathrm{nm}^{2}$ ); vertical dotted lines $=$ saturation vapor pressures at given temperatures. The 2-D Wulff shapes depicted in (a) indicate the crystal habits representing the conditions of region I and II.
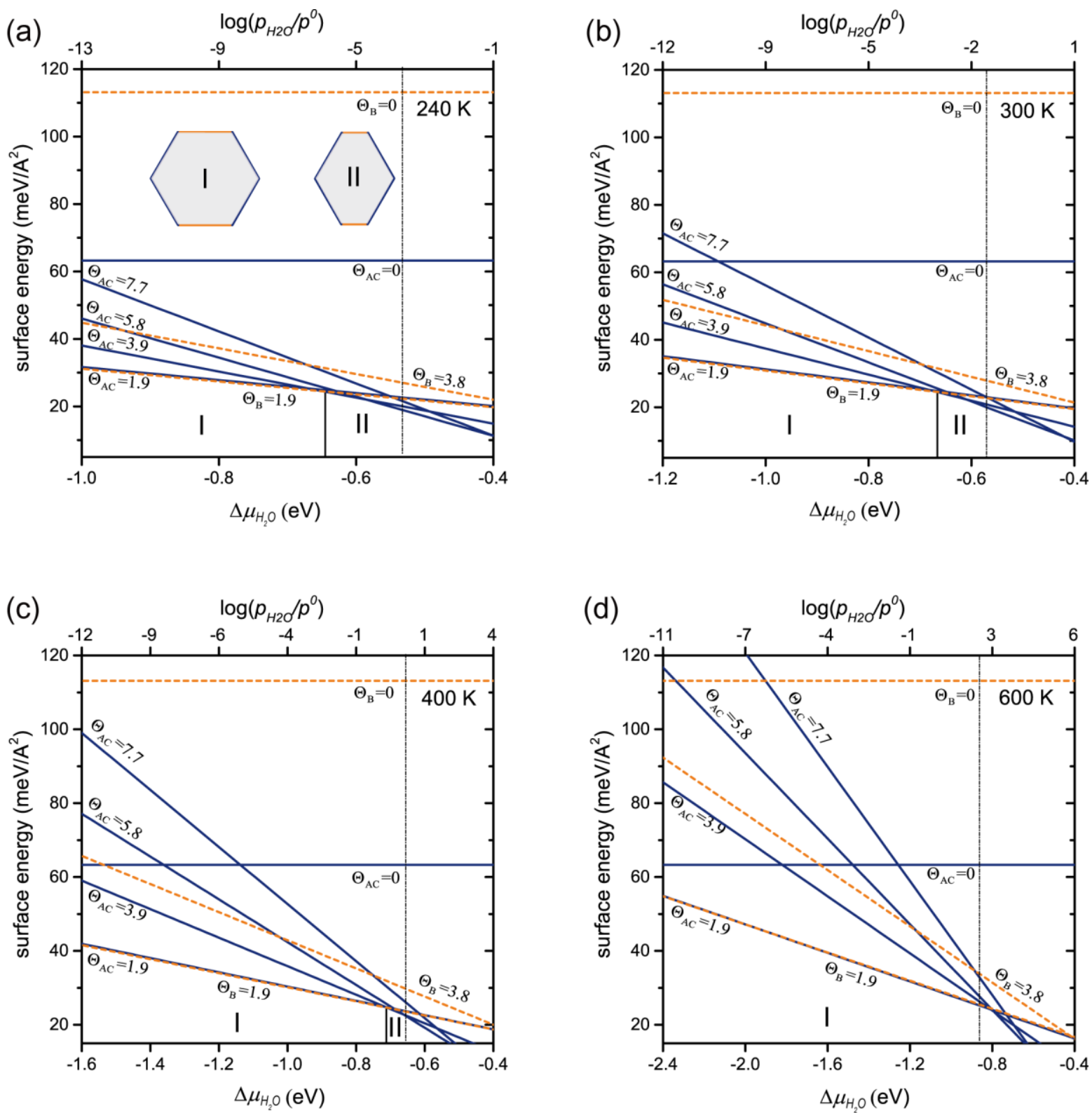
Figure 5. Free energy $\left(\Delta G_{\mathrm{EF}}\right.$ ) in the incorporation of the EF defect into bulk pyrophyllite as a function of water chemical potential $(\Delta \mu)$ at (a) $300 \mathrm{~K}$, (b) $400 \mathrm{~K}$, and (c) $600 \mathrm{~K}$. The partial pressure scale corresponding to the water chemical potential is provided on the top horizontal axis $\left(p^{0}=1 \mathrm{~atm}\right)$. The EF defect ratio is provided in parenthesis. Solid lines = free energies with the vibrational energy contribution; dashed lines = free energies without the vibrational energy contribution; vertical dotted lines $=$ saturation vapor pressures at given temperatures .

(a)

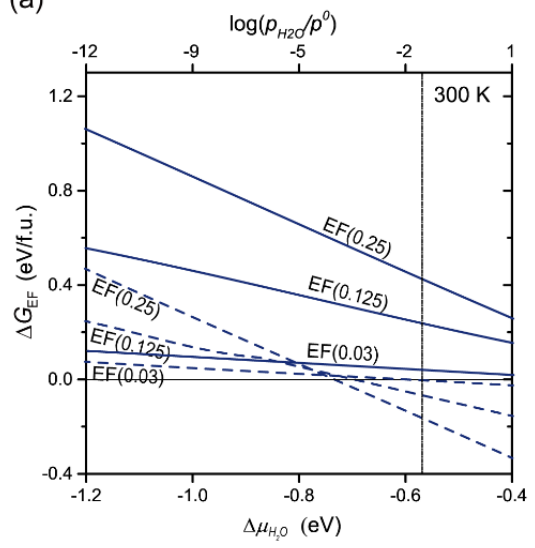

(b)

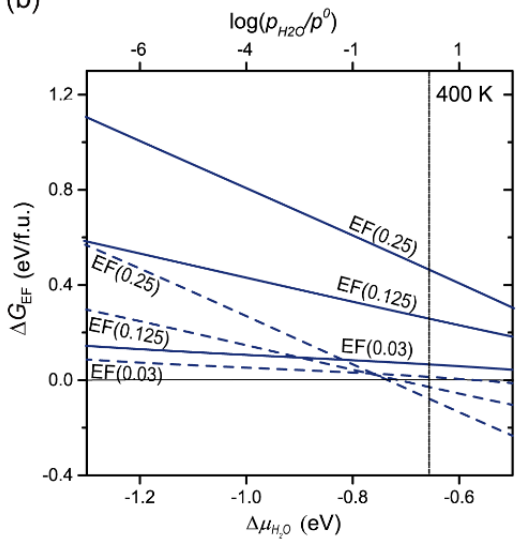

(c)

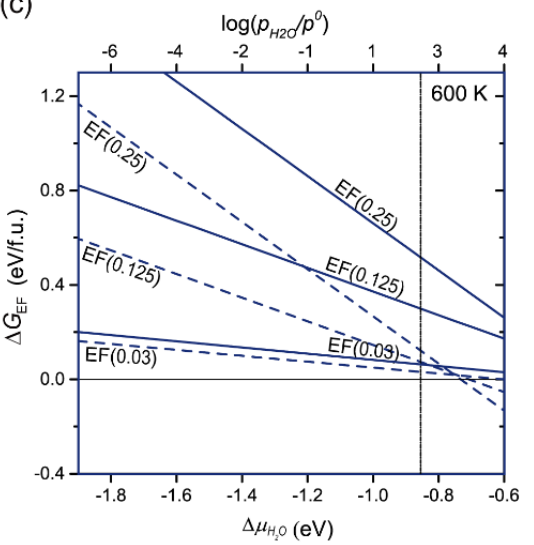


Figure 6. AC edge surface model with EF defects viewed (a) parallel and (b) perpendicular to the edge. Inverted $\mathrm{Si}(1)$ is labeled in (a). The five-coordinated, trigonal-bipyramidal $\mathrm{Al}\left({ }^{[\mathrm{V}]} \mathrm{Al}\right)$ and the bridging $\mathrm{O}\left(\mathrm{O}_{\mathrm{sb}}\right)$ that result from a hydrolysis/proton transfer are labeled in (b). Color scheme: red $=\mathrm{O}$; white $=\mathrm{H} ;$ magenta $=\mathrm{Al}$; ochre $=\mathrm{Si}$.
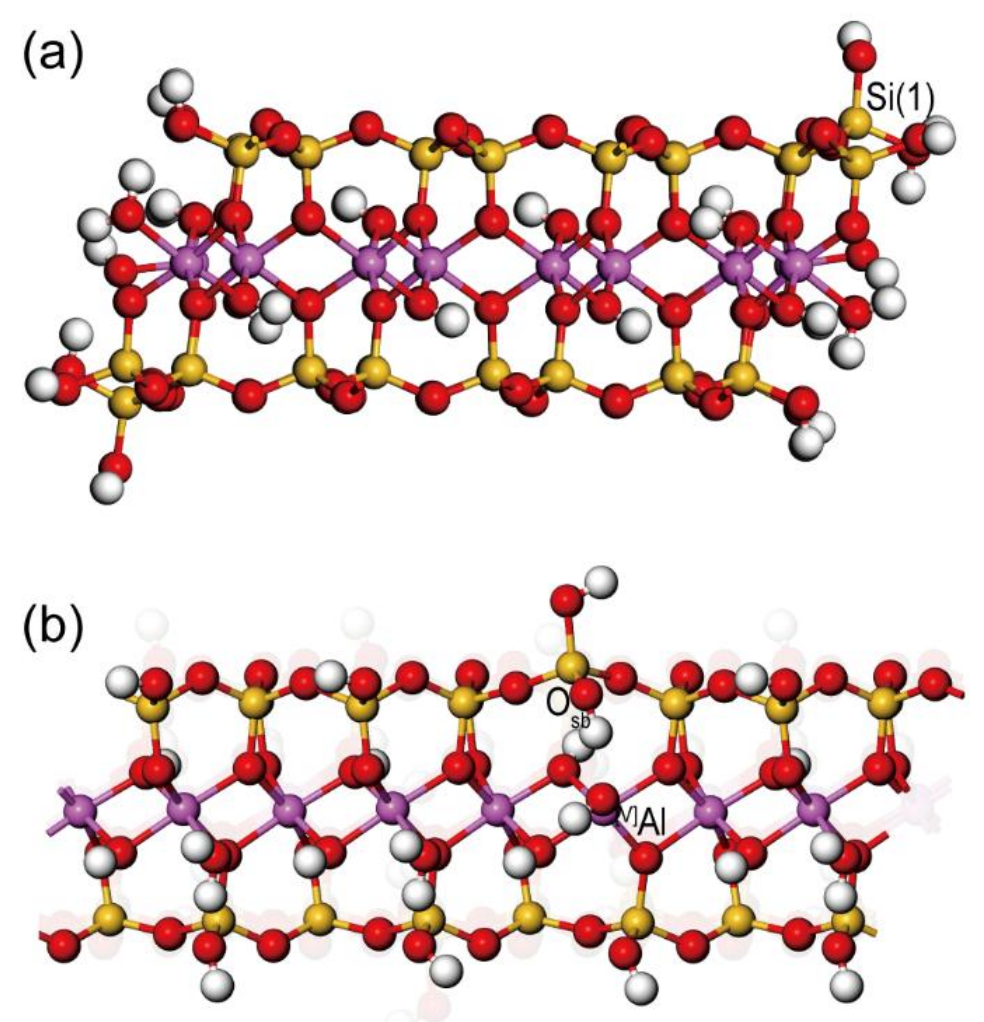
Figure 7. Surface free energies of the EF-defected AC edges $\left(\Theta=3.9 \mathrm{H}_{2} \mathrm{O} / \mathrm{nm}^{2}\right)$ (solid magenta lines, $\mathrm{EF}_{\mathrm{AC}}$ ) as a function of water chemical potential $(\Delta \mu)$ at (a) $240 \mathrm{~K}$, (b) $300 \mathrm{~K}$, (c) $400 \mathrm{~K}$, and (d) $600 \mathrm{~K}$. The EF defect ratio is provided in parenthesis. The surface free energies of defect-free $\mathrm{AC}$ and $\mathrm{B}$ edges at defined surface coverages $\left(\Theta_{\mathrm{AC}}\right.$ or $\left.\Theta_{\mathrm{B}}\right)$ are shown as solid blue and dashed orange lines, respectively.
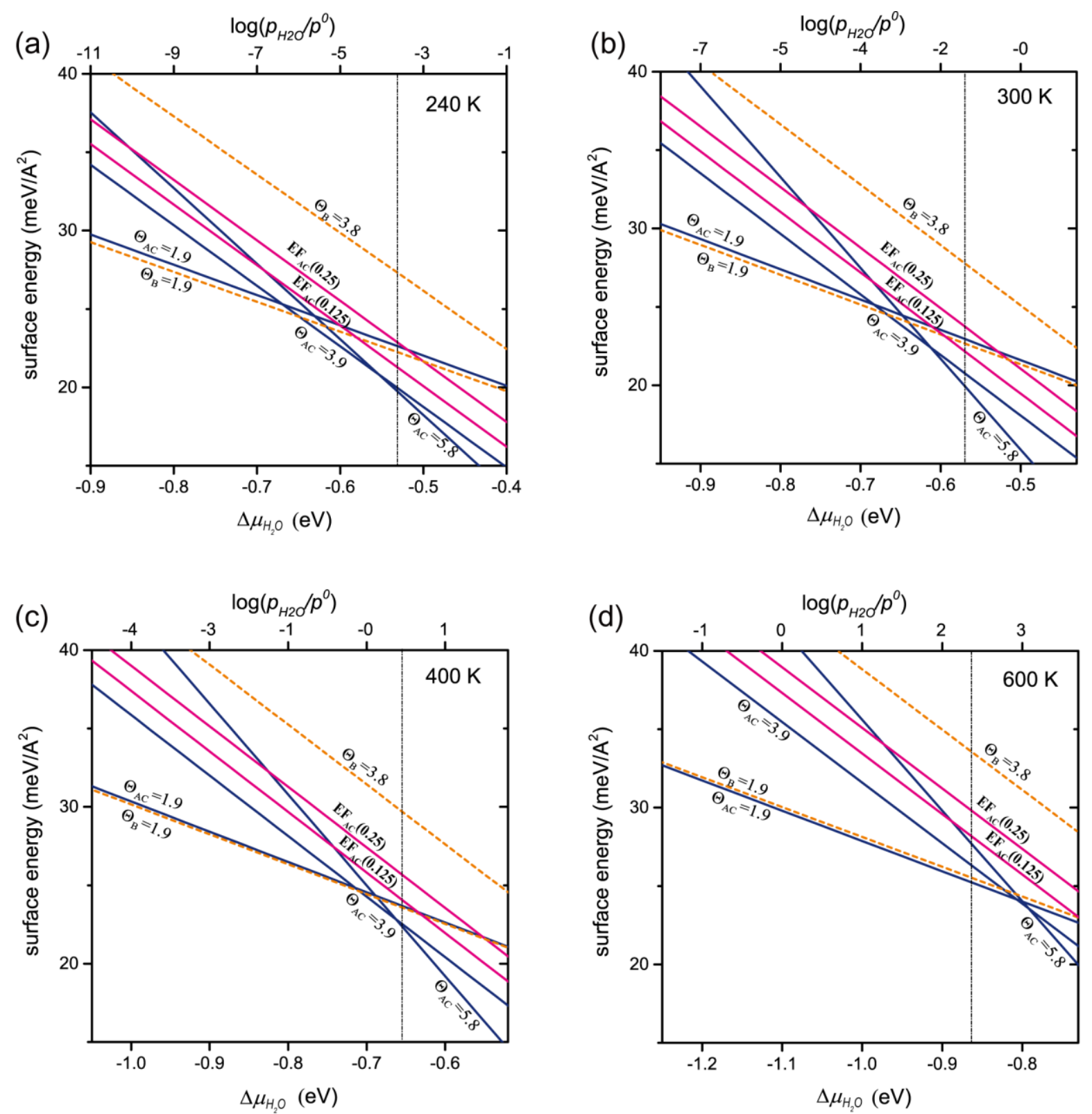
Figure S1. Vibrational energy contribution of the adsorbed water molecules $\left(\gamma^{\mathrm{vib}}\right)$ to the surface free energies of the pyrophyllite AC edge surfaces. $\Theta=$ water coverage (in $\mathrm{H}_{2} \mathrm{O} / \mathrm{nm}^{2}$ ).

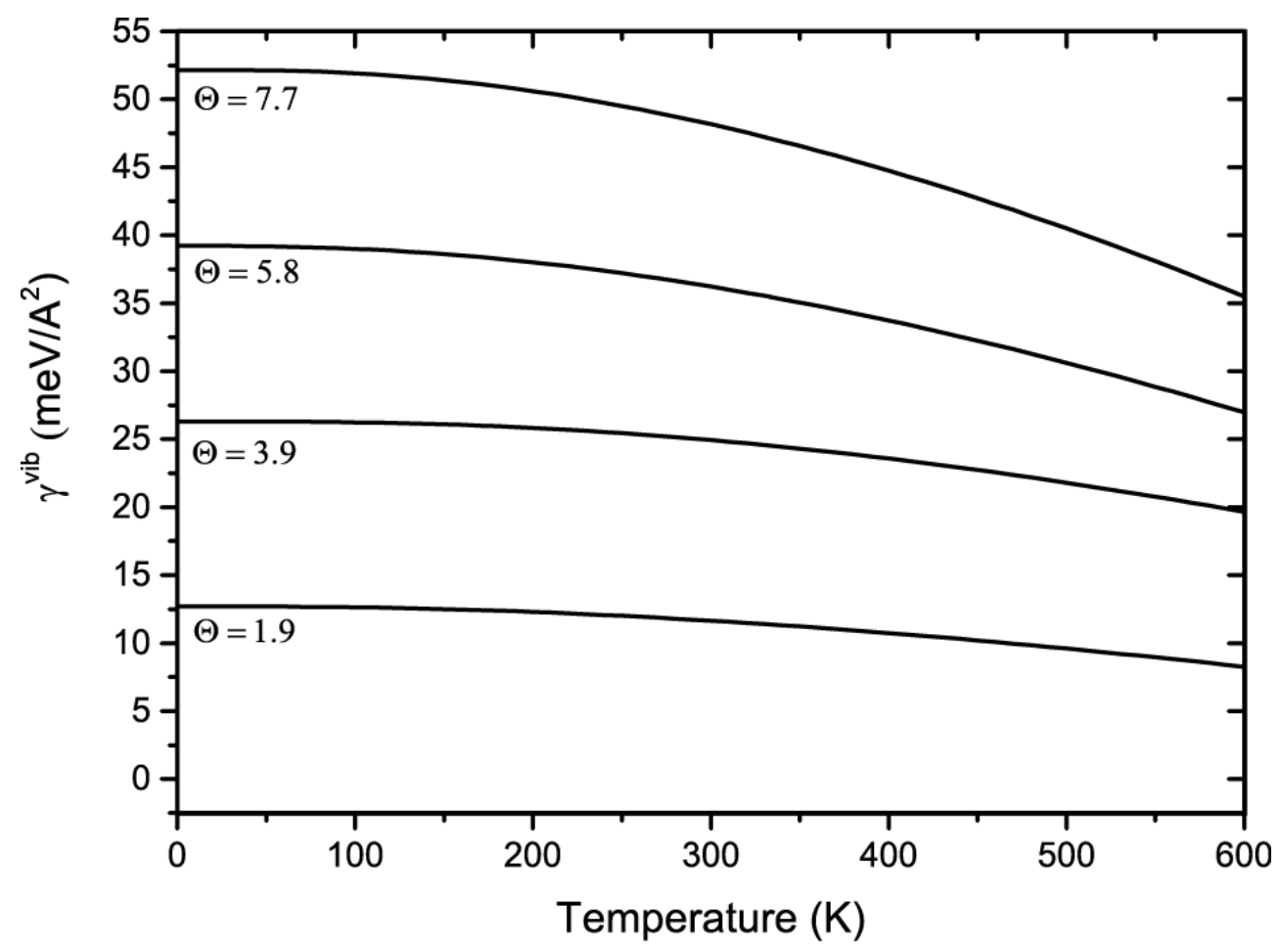

